\title{
Plausibilitat d'un ancestre comú entre les obres mitològiques de Joan Roís de Corella i les Transformacions de Francesc Alegre
}

\author{
Pere Bescós \\ Universitat Pompeu Fabra \\ pere.bescos@upf.edu \\ https://orcid.org/OOOO-OOO2-I333-6887 \\ Received: o7/IO/2OI9; accepted 02/04/202O \\ DOI: https://doi.org/I0.7203/MCLM.7.I589I
}

\begin{abstract}
Plausibility of a common ancestor between the mythological proses of Joan Roís de Corella and Francesc Alegre's Transformacions
\end{abstract}

\begin{abstract}
Between the Transformacions of Francesc Alegre (c.I452 - c.I5o8) and the mythological proses of Joan Roís de Corella some textual coincidences have been detected. Not without reservations, these coincidences have been explained as Corellas influence on Alegre. This is the most satisfactory explanation, given Alegre's admiration and imitation of Corella's prose, and Corella's huge fame in the second half of the fifteenth century. However, Alegre knew earlier versions of Ovid's Metamorphoses, such as that by Francesc de Pinós (I416-I475), or the anonymous Castilian version, both nowadays lost. And perhaps these versions were known by Corella too. The textual coincidences of these two authors have been analyzed here to determine if they respond to Corella's direct influence or if, in some cases, they could be explained

by a common ancestor.
\end{abstract}

\section{KEYWORDS}

Joan Roís de Corella; Francesc Alegre; Francesc de Pinós; Ovid in the Middle Ages; Metamorphoses; Les metamorfosis; medieval translations; Giovanni Bonsignori; prince Charles of Aragon (Charles of Viana).

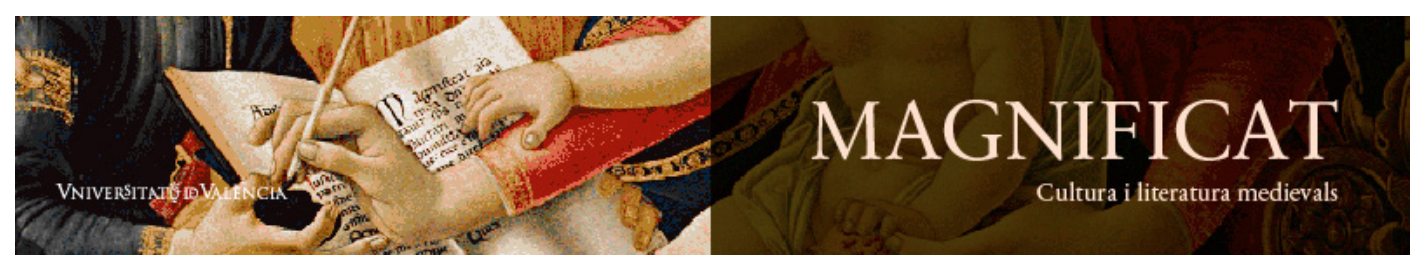

Magnificat Cultura i Literatura Medievals 7, 2020, I03-134. http://ojs.uv.es/index.php/MCLM

ISSN 2386-8295 
RESUM

Entre les Transformacions de Francesc Alegre (ca.I452 - ca.I5o8) i les proses mitològiques de Joan Roís de Corella hom hi ha detectat una sèrie de coincidències textuals explicades en conjunt, tot i que amb reserves, per una influència corellana. Aquesta resulta l'explicació més satisfactòria, atesa l'admiració que Alegre sent per Corella, la imitació que fa de la seva prosa i perquè el valencià és un autor consagrat a la segona meitat del segle XV. Ara bé, Alegre coneix versions anteriors de Les metamorfosis d'Ovidi, com la de Francesc de Pinós (I4I6-I475) o l'anònima castellana, avui perdudes, versions potser també conegudes per Corella. En aquest estudi analitzem críticament les coincidències textuals d'aquests dos autors amb l’objectiu de determinar si totes responen a una influència corellana o si, en algun cas, poden remetre a un ancestre comú.

PARAULES CLAU

Joan Roís de Corella; Francesc Alegre; Francesc de Pinós; Ovidi a l’Edat Mitjana; Les metamorfosis; traduccions medievals; Giovanni Bonsignori; Carles d’Aragó (Carles de Viana).

Pere Bescós. 2020. 'Plausibilitat d'un ancestre comú entre les obres mitològiques de Joan Roís de Corella i les Transformacions de Francesc Alegre', Magnificat Cultura i Literatura Medievals, 7: IO3-I34, DOI: https://doi.org/IO.7203/MCLM.7.I589I (G) Br

TAULA DE CONTINGUTS

I Introducció - IO5

2 Passatges equipol-lents entre Corella i Alegre - IO

${ }_{3}$ Passatges comuns entre Corella i Alegre - II 4

3.I. Afegitons i addicions - II4

3.2. Alteracions, substitucions iomissions dels originals - II6

4 Un passatge comú significatiu entre Corella i Alegre - 120

5 Conclusions - I24

6 Obres citades - I26

7 Annex. El vincle històric possible: la cort del príncep Carles d'Aragó - I3O 


\section{b米}

\section{Introducció}

$\mathrm{F}$ rancesc Alegre (ca.I452 - ca.I5o8) va traduir Les metamorfosis d'Ovidi al català, versió coneguda amb el nom de Transformacions i estampada a Barcelona el I494. A aquesta traducció, Alegre va afegir-hi un comentari als mites ovidians conegut amb el nom d'Al-legories. Les Transformacions és la primera traducció catalana de Les metamorfosis que conservem, però no la primera de què tenim notícia, perquè amb anterioritat Francesc de Pinós (ca.I4I6 - ca.I475), camarlenc, ambaixador i membre de la cort del príncep de Viana, n’havia fet una versió parcial, «uns quants libres», segons

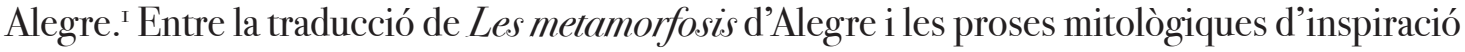
ovidiana de Joan Roís de Corella, hom hi ha detectat una sèrie de coincidències de tipologia diversa, explicades en conjunt, tot i que amb les oportunes reserves, per una influència corellana. ${ }^{2}$ Històricament, per l'admiració que Alegre sent per l'obra de Corella, per la imitació que fa de la seva prosa i obra, i atès que el valencià és un autor consagrat a la segona meitat del segle XV, aquesta resulta l'explicació més satisfactòria. Ara bé, arran de l'existència de versions anteriors, com la de Pinós, poden ser algunes d'aquestes coincidències, en realitat, restes d'una versió primerenca de Les metamorfosis avui no conservada? El propòsit de l'article és estudiar, a nivell textual i històric, la plausibilitat d'aquesta opció.

A les Transformacions, Alegre segueix fonamentalment dos originals: el llatí d'Ovidi i la traducció italiana de Giovanni Bonsignori (s. XIV). ${ }^{3}$ A l'epíleg Alegre critica el mètode seguit pels traductors anteriors, que segons ell no han preservat el dictat poètic del text d'Ovidi. Més o menys conseqüent amb la seva crítica, duu a terme dues operacions rellevants: depurar el text italià de Bonsignori a partir del vers llatí, i dissociar traducció (Transformacions) de comentari (Al-legories). ${ }^{4}$ Alegre, però, no manté el mateix grau d'exigència de depuració tot al llarg de l'obra, sinó que es mostra variable. No obstant aquesta variabilitat, per la seva tendència de depuració, el barceloní factura una traducció més propera a l'original que no la tradició anterior que critica. A l'epíleg de les Transformacions, a més d'aquesta crítica a les versions anteriors, Alegre aprofita per repassar i

I. Agraeixo a Jaume Torró les apreciacions que ha fet a aquest treball, així com els comentaris dels revisors/es; alguns mèrits són seus, els errors únicament responsabilitat de qui signa. En aquest treball s'amplia i concreta el que s’havia exposat preliminarment a Bescós (20I9b). Per a l'entorn del príncep, vegeu la síntesi de Rodríguez Risquete (2OII: I, 63-73).

2. En tractar el Raonament de Corella, Wittlin (I993: 34I n. 4I) cregué oportú comparar-lo amb les Transformacions d’Alegre i aportà un passatge, intuint alguna relació entre ambdós textos. També Pellissa (2OI9: 25 n. I3), en vincular les Transformacions a les proses de Corella, apunta la possibilitat que algun dels casos que analitza pugui provenir de Pinós o de la versió castellana perduda.

3. Per als originals de les Transformacions, vegeu Riquer (1934), Badia (1993), Torró (1994), Alcina (I998), Bescós (2OO7, 2OII, 2OI4 i 2OI9b), Compagna (2OI2 i 2OI4), Moncunill (2OI5), Pellissa (2OI7) i Reginato (2OI8). Les professores Gerlinde Hüber-Rebenich i Beatrice Wyss, de la Universitat de Berna, treballen en l'edició del text de Del Virgilio, l’original de Bonsignori. La primavera del 20I5, per invitació de la professora Hüber-Rebenich al seminari de l'Institut für Klassische Philologie de la Universitat de Berna, vaig presentar uns primers resultats sobre les fonts habituals d'Alegre a les seves Transformacions, especialment en relació al text de Del Virgilio.

4. Alegre treballa a dues bandes amb dos originals principals. Hom pot sostenir que depura Bonsignori amb Ovidi, o que tradueix el poeta romà afegint-hi passatges de Bonsignori. Tot i l'aparent semblança entre les dues formulacions, no és la mateixa metodologia. La presència continuada de l'element italià en la traducció d'Alegre indica que cal entendre la primera opció. En relació al mètode de traducció a les Transformacions, vegeu especialment Bescós (2OIgb: I5-49). 
demostrar que coneix part de la tradició textual de l’Ovidi medieval (TF Súplica; Bescós 2OIgb: 424):

Bé és ver que en temps passat un Johan de Virgili, natural de Toscana, escriví en prosa latina bé digne de aquell temps la substància de les Transformacions del poete Ovidi. No he volgut dir la flor, perquè, com compendran los discrets legidors, és tal traductió composta de espines, dexant la multitut de odoríferes flors ab què lo nostre poeta ornà lo seu scriure, ajustant lo dit toscà [Del Virgilio] ab les faules de Ovidi, trocejades, moltes al-legories segons sa fantasia. De aquest latí gros fon tret lo que és en toscà [Bonsignori], y del toscà no sol lo castellà mes uns quants libres en català, traduïts del toscà en temps passat per lo noble don Francesch de Pinós. Totes aquestes traductions no són ignorades del meu traduidor, qui ans que molts dels detractors sabessen confegir ne ajustar dos letres les havia ya vistes.

Alegre indica que el noble Francesc de Pinós ha traduït, amb anterioritat i a partir de Bonsignori, uns quants llibres de Les metamorfosis. Potser Alegre ha llegit el text de Pinós i n’ha deduït la font, o bé la versió de Pinós duia algun tipus de paratext -un epíleg o un pròleg-amb aquesta informació. Com que no conservem la versió de Pinós, les afirmacions d'Alegre són indemostrables, però a tenor de la fiabilitat de la resta de dades que dóna a l'epíleg, tampoc cal posar-les en dubte. ${ }^{5}$ A banda de la traducció de Pinós, Alegre també fa referència a una traducció castellana, feta igualment a partir de Bonsignori; potser aquella que va promoure el Marquès de Santillana, avui perduda, de què parla en una carta al seu fill don Pedro González de Mendoza a mitjan segle Xv (Gómez MorenoKerkhof I988: 456-457):

A ruego e instançia mía, primero que de otro alguno, se han vulgarizado en este reyno algunos poetas, assí como la Eneida de Virgilio, el Libro mayor de las transformaciones de Ovidio, las Tragedias de Lucio Anio Séneca e muchas otras cosas en que yo me he deleytado fasta este tiempo e me deleyto.

5. L'única referència de l’època on es dóna el nom de Del Virgilio com a original de la traducció de Bonsignori és aquest text d'Alegre (Guthmüller I997: 66). En primer lloc Alegre cita el resum de Giovanni del Virgilio ( «ohan de Virgili»), professor de gramàtica i retòrica al Studio di Bologna. Al voltant de I322, a partir d'unes lliçons universitàries sobre Les metamorfosis, Del Virgilio escriu un resum del text ovidià (en «latí gros» segons Alegre), conegut amb el nom d'Expositio. A continuació d'aquest resum, Del Virgilio afegeix unes Allegorie per comentar els mites a partir del «sensus historicus, naturalis e moralis» (Guthmüller s997: 93). L'obra de Del Virgilio consta, doncs, de dues parts, en prosa i en llatí: (a) l'Expositio o resum de Les metamorfosis, i (b) les Allegorie o comentari al text. Del Virgilio confecciona per separat traducció i comentari, motiu pel qual les Allegorie circularen amb els versos llatins d’Ovidi copiats com a pauta per situar l'explicació (Ghisalberti I933: 3I). Per la seva naturalesa propedèutica, el comentari de Del Virgilio va gaudir d'una fama important com a accessus a Les metamorfosis. Mig segle més tard, entre I375 i I377, Giovanni Bonsignori tradueix en italià les dues parts del llibre de Del Virgilio. Aquest italià és anomenat per Alegre «lo que és en toscà». Bonsignori, però, distribueix el text de manera diferent: la seva traducció de l'Expositio passa al lloc que abans ocupaven els versos originals d'Ovidi a les Allegorie, que també tradueix (Ardissino 20or). És a dir, Bonsignori elimina els versos originals d’Ovidi que servien com a pauta, i en el seu lloc hi emplaça la seva versió italiana de l'Expositio, tot barrejant traducció i comentari en un sol text. Alegre, com sembla indicar el passatge, remunta aquesta barreja a Del Virgilio: «ajustant lo dit toscà [Del Virgilio] ab les faules de Ovidi, trocejades, moltes allegories segons sa fantasia». Però aquesta afirmació d’Alegre no encaixa amb la història textual que la crítica ha traçat per als textos de Del Virgilio i Bonsignori. Potser hi va haver un còdex de Del Virgilio que s’ha perdut amb la disposició que indica Alegre? Potser Alegre s'està referint als versos originals d'Ovidi amb l'expressió «les faules de Ovidi», i no pas a l'Expositio de Del Virgilio? En aquest segon supòsit podríem llegir aquest passatge simplement com una referència a la distribució textual de les Allegorie de Del Virgilio. Sigui com sigui, Bonsignori comença traduint el text d'Ovidi ajudat tímidament pel text de Del Virgilio, en tant que accessus, però a finals del llibre primer (capítol d'Io), passa a dependre de l'Expositio, tot i que retorna al llatí d'Ovidi en alguns capítols del llibre segon (Ardissino 20oI). D’alguna manera la traducció italiana representa, en relació al text del professor bolonyès, un apropament a l'original llatí, però encara depèn fonamentalment del text de Del Virgilio. 
En la transmissió textual traçada per Alegre no hi ha cap referència a la tradició francesa. No s'esmenta la traducció en vers Ovide moralisé d'inicis del segle XIV, tampoc l'Ovidius moralizatus (mitjan segle XIV), ni la impressió La Bible des poètes, estampada a Bruges el I484. Aquest bandejament teòric de la tradició francesa, que es correspon amb els originals principals als quals recorre Alegre, pot respondre a motius diversos: $(a)$ la tradició italiana efectua, a més de la interpretació moral i cristiana d'Ovidi, una interpretació dels mites en sentit històric i natural, també atractiva per Alegre; (b) Alegre té més contacte i facilitat per accedir a la tradició italiana que no a la tradició francesa; $(c)$ la feina d'Alegre s'emmarca dins d'una tradició de Les metamorfosis de forta influència italiana, de la qual eventualment també formà part, fins on podem saber i segons les afirmacions d'Alegre, la versió de Francesc de Pinós. Es tracta d'una tradició ovidiana relacionada amb la cort, punt de trobada d'escriptors com Corella, Martorell o Torroella, i hàbitat de nobles com Francesc de Pinós. Recordem que, en conjunt, la tradició ovidiana en català, tot i la presència notable en obres del període, ha deixat un rastre documental i arxivístic poc representatiu de la seva influència literària real (Pujol 20I8: 73-74). ${ }^{6}$ D'aquí l'interès principal de la informació que puguem extreure de la filiació textual entre Corella i Alegre, especialment si ens pot confirmar la presència d'alguna obra rellevant avui perduda.?

Ara bé, el propòsit d'aquest estudi no és demostrar l'existència del text perdut de Pinós, perquè, com dèiem, no cal dubtar-ne ni es pot demostrar; tampoc qüestionar la influència de Corella en Alegre, innegable en obres com la Faula, sinó estudiar la possibilitat que, a més de l'admiració que Alegre sent per Corella -i que es manifesta a nivell estilístic a les Transformacions i en obres com la Faula-, sigui plausible situar un ancestre comú, és a dir, una traducció anterior de Les metamorfosis avui perduda, entre els originals amb els quals treballaren els nostres autors.

Per dur a terme la nostra anàlisi, hem classificat les coincidències textuals Corella-Alegre en dos grans grups: ( $a$ ) passatges equipol-lents Corella-Alegre, és a dir, textos semblants als dos autors, però en els quals no podem demostrar una relació o filiació perquè són coincidències que es poden explicar per separat; i $(b)$ passatges inequívocament comuns Corella-Alegre, això és, passatges que no poden explicar-se per separat i que demostren una relació o filiació entre les obres dels nostres autors. La majoria d'aquests passatges $(b)$, tot i demostrar un vincle textual Corella-Alegre, no informen de com aquest s'estableix ni sobre el seu punt d'origen, a excepció del I6, cas significatiu que, com veurem, ofereix informació en aquest sentit.

\section{${ }_{2}$ Passatges equipol·lents entre Corella i Alegre}

En els casos classificats com a equipol-lents entre l'obra mitològica de Corella i les Transformacions hi ha passatges on, tot i trobar-se un text semblant, la coincidència pot explicarse per separat. Corella i Alegre escriuen segons un mateix model de prosa i les seves obres es contextualitzen en un mateix moment històric de recepció de Les metamorfosis ovidianes. Cal, doncs, estar molt atents a aquests dos aspectes, l'estil comú i la tradició medieval d’Ovidi, i

6. Amb l'excepció de les conservades Heroides de Guillem Nicolau i d'aquestes Transformacions d'Alegre. 7. Si bé en el cas d'Alegre és evident la relació del seu text amb el de Bonsignori, aquesta també s'entreveu en Corella, però més feblement, atès que Corella adapta els textos amb els quals treballa i els reelabora creativament, cosa que en dificulta la comparació. En el cas del valencià, hom ha resseguit la seva adaptació d'Ovidi, el de les Heroides i el de Les metamorfosis, però no la connexió amb Bonsignori (hi ha algun element a Pellissa 20r9: 29-30). En aquest sentit, si ens fixem en dos passatges de la Lamentació de Mirra (els núm. I5 i i6 d’aquest treball), trobem també en Corella una possible relació amb Bonsignori, com veurem més endavant en analitzar aquests casos. 
comprovar si algunes semblances són possibles per separat.

En el cas següent, per exemple, tot i la semblança, textualment no podem demostrar una filiació entre les obres dels dos autors, perquè les relacions es poden explicar, en part, a partir de l'estil de prosa comú a Alegre i Corella, i a partir de fonts sovintejades, com la Genealogia de Boccaccio. El passatge és de l'episodi de Biblis: ${ }^{8}$

I. Ovidi: me miseram! tacitae quid vult sibi noctis imago? | quam nolim rata sit! cur haec ego somnia vidi? | ille quidem est oculis quamvis formosus iniquis | et placet et possim, si non sit frater, amare, | et me dignus erat; verum nocet esse sororem. | dummodo tale nihil vigilans committere temptem | saepe licet simili redeat sub imagine somnus; | testis abest somno, nec abest imitata voluptas. | pro Venus et tenera volucer cum matre Cupido, | gaudia quanta tuli! quam me manifesta libido | contigit! ut iacui totis resoluta medullis! | ut meminisse iuvat! quamvis brevis illa voluptas | noxque fuit praeceps et coeptis invida nostris [...] quid mihi significant ergo mea visa? quod autem $\mid$ somnia pondus habent? an habet et somnia pondus? ('Ai de mi! Doncs ¿què són, en la nit callada, unes ombres? Ah, si no fos veritat! ¿Per què he tingut aquest somni? Ell és formós, sens dubte, per molt malament que se’l mirin, i podria de grat, si no fos germà meu, estimar-lo, i és ben digne de mi; però ser-ne germana em fa nosa. Mentre un acte semblant no l'intenti cometre desperta, ja pot tornar ben sovint un somni que em duu tals imatges: prou que el somni els plaers representa, i no té testimonis. Tendra Venus i tu, volàtil Cupido, amb ta mare, quant de goig he sentit! Quins delits del tot manifestos m'han agafat! Com jaient fins el fons dels molls em fonia! Que n’és, de bo, el record! Ha estat la nit fugissera, tant com breu el plaer, recelant de la nostra esperança [...] Què significa, però, el que he vist en imatge? I un somni ¿quina importància té? ¿O un somni també té importància?' (Parramon 1996: 242-243), Met. IX.474486 [...] IX.495-496); Bonsignori: Perché vengono questi somnii? in verità costui pò bene essere amato da me, s'elli non fosse mio fratello. Ma almeno poi che io non posso de dì avere el mio volere, almanco l'averò io de notte soniando, e questo non porrà persona sapere. [...] Per certo questo mio pensiero è uno grande peccato, che è a pensare [...] che la sorella ami el fratello de carnal desiderio? (Ardissino 200I: 458-459); Genealogia: «Hunc circa passim varias imitantia formas Somnia vana iacent totidem, quot messis aristas, Silva gerit frondes, eiectas litus harenas» [=Met.XI.59I-6I5] etc. [...] Secunda insomnium nuncupatur a premeditatione causatum, ut Tullius affirmare videtur in libro Reipublice dicens: «Fit enim sepe ut cogitationes sermonesque nostri pariant aliquid in somno, quale de Homero scribit Emnius, de quo videlicet sepissime vigilans solebat cogitare et loqui» etc. In hac igitur specie somnii amans dilectam sibi puellam in amplexus eius occurrentem aspiciet, aut fugientem miserrimus exorabit. Nauta tranquillum mare navemque pansis velis sulcantem, aut tempestate periclitantem aspiciet. Sic et agricola frustra letabitur letas arvis intuens segetes depastasque plorabit. Ingurgitator pocula exhauriet; ieiunus cibos aut optabit, aut faucibus vacuis devorabit appositos. De premeditatis autem a Didone saucia, visa quidam volunt, eo quod videatur a Virgilio ostensam premeditationem dum dicit: «Multa viri virtus animo multusque recursat Gentis honos, herent infixi pectore vultus Verbaque» etc. Et sic tamquam ex premeditatione proveniens videtur esse insomnium. Verum quoniam ex affectione procedunt una cum somno in auras evanescunt, ut ipse idem Virgilius dicit: «Sed falsa ad celum mittunt insomnia Manes» (Gen. I.3I; Zaccaria I998: I64-I66); Lamentació de Biblis de Corella: $\mathrm{O}$, més que altra atribulada! E quina fi portarà aquest sompni? Yo bé veig que la bellea de Cauno no mereix sinó per mi ésser possehida, però nou-me ésser-li germana. Mas crech que los sompnis no són del tot vans e, si u són, la vanitat del món nom pot toldre l'estrem delit del qual ells m’an fet report. E plagués a Déu en tant plaent dormir passàs ma vida. Però, dolre’s ni alegrar-se de les coses passades fallença de seny ho causa. Mas assajaré si, ab mudat nom, poré enganar a Cauno e que sia nora de mon pare, puix altra que yo no y veig més digna mare de mos nebots. O, Cauno! E, si altra

8. En relació a aquest passatge, vegeu també Pellissa (2019: 26), on s'analitza diferentment. Per al text llatí seguim l'edició de Tarrant (2004), contrastada puntualment amb l'edició de Jahn (I832), que recull un bon nombre de variants no col-lacionades a Tarrant (2004). 
és ta muller, yo not seré sinó germana e no tendré ab tu sinó lo deute que a mon voler contrasta. Millor han elegit los déus, liberts de nostres leys, car los tàlems de Thetis possehís Occèano. E Saturno és alegre que Opis sia mare e tia de sos fills. E Juno trihunfa en lo cel, no en nom de germana, mas com a muller del gran Júpiter (Martos 200Ia: 200); Transformacions: Ay, mesquina de mi! Què vol dir aquest somni de la callada nit? Com és passat més prest que no volguera! Per què veig yo tals somnis? Que aquell, posat sia gentil, té los ulls molt inichs y desenamorats, mes plau-me tant, que, si no·m fos germà, lo poguera amar y certament fóra digna de mi, mes nou-me, trista, ésser-li yo germana [om. vv. 479-405] O, Cayno, si podia yo, mudant- $\{80 a\}$ me lo nom, ésser ab tu casada, quant bé poríam ésser gendre y nora de un pare! Y ya fessen los déus totes coses comunes en nosaltres, sinó los avis, que no·m daria res fosses més de mi noble! $\mathrm{A}$, més gentil dels hòmens, e qui serà la benaventurada que faràs ésser mare? Mala per mi me ha donat la sort ensemps ab tu ésser filla d'un pare. Aquella sola cosa, qui mos desigs contrasta, tench comuna ab tu. Què, donchs, me signifiquen aquestes visions? Quin pes han aquests somnis? Vanes són totes les lurs promeses? Millor ho fan los déus casant ab sas germanes. No és casat Saturno ab Ope, Occeano ab Tetis, y el regidor del gran mont de Olimpo ab sa germana Juno? Però los déus tenen ses leys! Y per què tempte yo mesclar les leys humanes, tan diverses de aquelles, ab les celestials? (TF IX.7; Bescós 2OIgb: 303); Transformacions: En lo mig d'una sala, dintre aquesta cova, estave un bell lit de fluxell, en lo quall jau lo déu del somni, ab membres relaxatss per soberga langor, y entorn d'ell, sots semblança de variades formes, jauen los somnis vans, tants com són les erestes dels camps $\{98 c\}$ o les fulles dels arbres (TF XI.8; Bescós 2OIgb: 34I);Al-legories: La segona espècia se nomena insomnium, causada de premeditació. En aquesta espècia somnia lo qui ama que és ab la anemorada, prenent delit ab ella o seguint-la pregant, lo mariner li par entrar en port ab veles plenes o enmig de la fortuna donar sinta a l'arbre, lo pagès sega ab pler o plore a les messes perdudes, lo embriach beu e lo dejú mou les barres al menjar va. E axí uns y altres per aquesta somnían coses premeditades, per on és di- $\{222 b\}$ ta insompnium, quasi in premeditatis sompnium. Lo que veem en aquesta espècia axí mateix és cosa vana y flaqua, e per ço diu Virgili: «falça ad celum mittunt insompnia manes» (AL IX.8).

La referència comuna, que hem subratllat, sembla remetre a un mateix text. Alegre tradueix el llatí an habet et somnia pondus?('té un somni importància / pes?') per «Vanes són totes les lurs [dels somnis] promeses?», i Corella té «Mas crech que los sompnis no són del tot vans». El verb (són / no són) i l'adjectiu (Vanes / vans) juguen un paper central en la percepció d'aquests dos testimonis com a un mateix text. En relació a l'objectiu del nostre estudi, el problema de casos com aquest és que no s’hi pot demostrar un text comú, ni es pot demostrar el contrari. D’entrada, tot i la semblança, la formulació és divergent, i mentre que en Corella els somnis no són del tot vans, Alegre es pregunta si les promeses dels somnis són vanes, construcció que remet a la qüestió ovidiana original. En segon lloc, el va com a traducció de pondus es pot explicar per l'ús que es fa en la prosa d'art de l'adjectivació com a recurs estilístic. En aquest tipus de prosa, com notem en autors com Torroella o Llull, hi ha un grup d’adjectius que són especialment recurrents amb un nom determinat, entre els quals precisament l'adjectiu $v a$. Per exemple, són freqüents crim + abominable, esperances + falses, inclinació + natural, pensaments + vans, pensament + cansat, sospirs + estroncats, etc. ${ }^{9}$ Així, la relació d'aquest adjectiu amb el substantiu somnis es podria explicar per l'estil de Corella i d’Alegre. A més, l’adjectiu, com a mínim en Alegre, també es pot explicar a partir de Boccaccio, precisament model d'aquesta prosa d'art, ja que en el capítol de la Genealogia on comenta la divinitat del Somni, llegim que els somnis «in auras evanescunt», passatge adaptat a les Al-legories en «Lo que veem en aquesta espècia [de somni] axí mateix és cosa vana y flaqua». Precisament en aquest passatge de la Genealogia, Boccaccio cita, com a exemple, un vers del llibre XI de Les metamorfosis: «Somnia vana iacent» (Met. XI.6I4), vers que Alegre tradueix com

9. En relació a l'ús de l'adjectivació per part d’Alegre, vegeu especialment Bescós (2OI9a: 64-8I). 
a «jauen los somnis vans» (TF XI.8; Bescós 2OIgb: 34I). Més enllà de si l'origen d’aquest estilema (somnis + vans) té alguna relació amb la prosa del Certaldès o amb el dictat d'Ovidi, el cas pot respondre a una coincidència d'estil, difícil, però, de detectar perquè es barreja amb l'original llatí. ${ }^{10}$ De fet, el Vanes d'Alegre sembla més plausible a partir de Boccaccio o d'altres punts on ell mateix tradueix el vana del llatí, que no a partir de Corella; però, és clar, l'adjectivació en Alegre, la decisió del barceloní de traduir el llatí pondus ('rellevància, pes, importància') per Vanes pot també seguir, si no directament la Lamentació de Biblis de Corella, sí una adjectivació llegida en algun punt de l'obra del valencià. A banda d'aquest adjectiu, la traducció del verb habet del llatí en són en Alegre i Corella, atesa l'alta freqüència d'ús del verb ésser, no sembla suficient per demostrar una filiació inequívoca en aquest punt. Sembla haver-hi una semblança, i per context literari i històric així ho qualificaríem, però res permet demostrar-ho a nivell textual. En resum, insistint en el marc teòric indicat, no hi podem demostrar un text únic als dos autors però tampoc una factura per separat. No sostenim, doncs, que no hi hagi una relació en aquest cas entre Alegre i Corella, sinó que passatges com aquest no poden ser tractats, en aquest estudi, com a lectures comunes. El mateix passa amb el cas següent:"I

2. Ovidi: [I] digitis morientibus ille retemptat | fila lyrae ('amb els seus dits moribunds mira de tocar de nou les cordes de la lira', Met. V.II7-II8); [2] Calliope querulas praetemptat pollice chordas | atque haec percussis subiungit carmina nervis ('Cal-líope tempta amb el polze les cordes, que es planyen, i entona aquesta cançó seguint els nervis percudits', Met. V.339-340); [3] pulsisque ad carmina nervis ('i polsant les cordes per cantar', Met. X.I6); [4] ut satis impulsas temptavit pollice chordas | et sensit varios, quamvis diversa sonarent, | concordare modos, hoc vocem carmine movit ('tan aviat com provà les cordes polsades i sentí que les diverses notes, tot i sonar diferent, concordaven, amb la veu va iniciar aquest cant', Met. X.I45-I47). Bonsignori: [I] om.; [2] E allora se levò su Caliope ed acconciò le corde alla cetira sua, acciò che potesse bene respondere, e propuse de cantare de Cerere e cominciò in questa forma (Ardissino 20OI: 272-273); [3] E come ave acconce le corde della cetira, incominciò in questa forma cantando a pregare (200I: 474); [4] avendo Orfeo desposte le corde della cetira al suo cantare, cantava e sonava in mezzo de quelli arbori e, chiamato che ave l'aiuto de Apollo e de Caliope, sì cominciò a cantare (200I: 48I); Parlament de Corella (Orfeu): Ans que en les arborades silves prengués possada, començà temprant moure los fils de la acordada arpa en melodia de proporció tan lamentable, que, fent principi al plorós cant de lamentació trista, los arbres, a qui la sua dolorosa veu pervenia, acostant-se a la entonada armonia, portant-li fresca ombra, lo defenien de la calor de Apollo [...] movent a piadoses peraules les tenors de la temprada arpa [...] Mas no tardà Orpheu moure los fils de la melodiosa arpa als acorts de semblants paraules [...] Tocant les primes de la acordada arpa en proporció de alegra armonia (Martos 200Ia: 253 i ss.); Transformacions (Perseu): [I] qui ab los dits, morint, assejà moure les cordes de la lira (TF V.r; Bescós 2OIgb: 204); Transformacions (Muses): [2] [Cal-líope] començà de temprar ab lo delicat polse las cordes de la arpa, seguint al so d'aquelles la sua plasent veu ab la següent cansó (TF V.4; Bescós 2OIgb: 2II); Transformacions (Orfeu): [3] començant ab sos dits a moure les cordes de la arpa, mesclant ab lo so de aquelles la sua gentil veu, axí dir comencà (TF X.I; Bescós 2OIgb: 309); Transformacions (Orfeu): [4] Y pus hagué, ab lo polse movent les cordes de la arpa, conegut concordar diversitat de sons ab tal dictat, mogué la sua veu (TF X.3; Bescós 2Orgb: 3І3).

El cas [3] d'Alegre («començant ab sos dits a moure les cordes de la arpa») ha estat relacionat per la crítica amb el corellà «començà temprant moure los fils de la acordada arpa», en llatí «pulsisque

IO. Per a la relació entre Corella i Boccaccio vegeu Martos (200Ib).

II. Aquest cas es troba analitzat, des d'una altra perspectiva, a Pellissa (2OI9: 30).

Magnificat CLM 7, 2O2O, IO3-I34. ISSN 2386-8295 
ad carmina nervis» ('i polsant les cordes per cantar'). ${ }^{22}$ De nou hi manca algun element que demostri una relació inequívoca i un text únic a Alegre i Corella. El text d'Alegre té dues diferències fonamentals en relació al de Corella: ab sos dits, que no es troba ni en Corella ni en Ovidi, i l'absència de temprant, sí present en el valencià, potser a partir de l'ovidià pulsis. A més, el llatí concordare [4], del mateix episodi d'Orfeu, pot explicar l'adjectiu acordada de Corella.

La resta de variacions d'Alegre en els quatre punts numerats d'aquest cas es poden explicar per l'original d'Ovidi. Així digitis [I], pollice [2,4], chordas [2,4], vocem [4], movit [4], i potser praetemptat [2]. A més, per exemple, la distribució en Alegre de l'ús dels mots arpa o lira sembla relacionar-se amb l'original llatí, perquè el català lira apareix l'únic cop que en Ovidi hi ha lyrae [I], i a la resta de casos, en què Alegre tradueix arpa, no s'especifica l'instrument. Corella mai fa servir el mot lira, potser arran de la seva adaptació d'Ovidi, però anomena les cordes fils (relacionat amb el llatí fila [I]), punt on Alegre té cordes, la seva traducció preferent i natural. I Corella tradueix fils però mai lira, que sí que trobem en Alegre. Atès que en el Parlament aquestes expressions es troben molt properes dins l'episodi d'Orfeu, si acarem els dos passatges d'Alegre d'aquest mite («començant ab sos dits a moure les cordes de la arpa» [3], «pus hagué, ab lo polse movent les cordes de la arpa» [4]) amb el text del Parlament («començà temprant moure los fils de la acordada arpa»), trobem que, a banda de les variacions que s'expliquen a partir d'Ovidi, tant en Alegre com en Corella, la semblança més evident no té una correspondència en llatí sinó amb l'italià. Es tracta del català començà / començant que, tot i que es pot inferir pel context, curiosament trobem en Bonsignori: «desposte le corde della cetira, incominciò» $\mathrm{i}$ «acconciò le corde alla cetira sua [...] e cominciò».

Però no tots els casos equipol-lents es relacionen més o menys amb un estil comú als dos autors, perquè algunes coincidències Corella-Alegre responen també a glosses o comentaris de la tradició de l'Ovidi medieval. ${ }^{13}$ En relació a un text tant divulgat, comentat i glossat com Les metamorfosis, les referències comunes Corella-Alegre que també es troben en algun punt de la tradició medieval poden ser explicades per separat, com mostra el cas següent: ${ }^{14}$

3. Ovidi: [Thereus] dat gemitus fictos (factos Rhen. Jahn I832: 382) commentaque funera narrat (Met. VI.565); Ovide moralisé: om.; Bonsignori: Filomena, tua sorella, è morta» e cominciò [Tereu] a piangere (Ardissino 200I: 322); Genealogia: [Tereus] veniens sordidatus ad Prognem Phylomenam maris nausea mortuam dixit (Gen. IX.8); Commento ai Trionfi: [Tereu] socto simulate lacrime facto

I2. Vegeu Pellissa (20r9: 30).

I3. A més dels casos que expliquem en el cos d'aquest article, Pellissa dóna vuit casos més (20r9: 23 i ss.). En relació al nostre objectiu, tot i les semblances, aquests casos no poden demostrar-se com a text inequívocament comú. Per exemple, a l'elaboració de l'episodi de Píram i Tisbe hi ha canvis comuns d'estil directe-indirecte, o una coincidència sobre si la iniciativa de la fugida recau més en Píram que en Tisbe; Corella encara usa el mot carçre dues vegades, i Alegre fa servir encarcerats referit a la condició de presos dels amants. A l'episodi de Mirra també detecta una semblança en la traducció d'un vers, on Ovidi diu que Cíniras, pare de Mirra, accepta en el llit culpable les seves pròpies entranyes [Mirra], referint-se a què Mirra és la seva filla i sang de la seva sang. Tant Corella com Alegre fan servir el mot sanch. Alegre té «Acceptà lo pare en lo culpable lit la sua sanch» (TF X.6; Bescós 2Orgb: 322), i Corella posa en boca de Mirra: «tenyint de verge sanch aquells tàlems en los quals fuy concebuda» (20ora: I83). L'ús del mot sanch és divergent en Alegre i en Corella, ja que el darrer es refereix al desflorament de Mirra, mentre que Alegre i Ovidi al-ludeixen al seu parentiu. Per últim indica també l'aparició de liberal / liberament amb el mot natura (2OI9: 2I) en els dos autors. A Corella trobem «natura líberament atorgua» (2OOIa: I77) i en Alegre «consent natura liberal» (TF X.6; Bescós 2OI9b: 3I8). No només l’adjectiu liberal (o el seu adverbi) és comú a la prosa d’aquests autors: terra liberal (TF I.3), «ministrant ... liberalment» (TF I.6) i déus liberals (TF IX.8) en Alegre, i «naturalea a Jàson líberament atorgava» en Corella, sinó que en Ovidi hi ha «natura remittit» ('la natura permet', Met. X.333) i en Bonsignori «permesso è dalla natura» (200I: 488), on l'acció del verb, en el context de l'oració, implica la generositat i liberalitat de la natura.

I4. En relació als casos 3, 4, 5 i 6, vegeu Martos (2OOIb: 540 i ss.) i Pellissa (2Or9: 24 i ss.). 
credere a Progne Philomena essere morta (BNF ms. Italien 552, f. 79r); Comentarials Trionfi: ${ }^{5}$ [Tereu] sots simulades làgremes fet creure a Prognes Ffilomena ésser morta (Recio 2009: 188); Comentario a los Trionfi: ${ }^{16}$ [Tereu] con lágrimas fingidas hizo entender a Progne que Philomena era muerta en el camino (Recio 2OI2: I28); Parlament de Corella: ab doloroses lagrimans paraules, a la muller [Procne] féu creure [Tereu] la germana Philomena de mal de la spantable mar havia dexat la vida (Martos 200ra: 276); Transformacions: Plorà lo ficte Tereu, y diu-li [a Procne] com és morta [Filomela] del treball de la mar (TF VI.5; Bescós 2OIgb: 239); Al·legories: om.

El passatge pertany a l'episodi de la violació i segrest de Filomela per part del seu cunyat Tereu (Met. VI.). No hem trobat d'on sorgeix la variació segons la qual Tereu, en arribar a palau, posa com a excusa a la seva dona Procne que la germana Filomela és morta a causa del mal de la mar. Ovidi només diu que Tereu narra uns commenta funera ('funerals imaginaris'). ${ }^{17}$ El fet que la Genealogia, que té maris nausea, sigui una enciclopèdia no permet establir-la com a l'origen d'aquesta variació, que probablement calgui remuntar a comentaristes anteriors. Els textos que contenen aquesta referència són la Genealogia, el Comentario a los Trionfi (versió castellana d'Antonio de Obregón, però no la traducció catalana anònima ni l'original italià de Bernardo Ilicino segons el ms. BNF Italien 552), el Parlament de Corella i les Transformacions. Com que Corella i Alegre recorren a la Genealogia per a les seves obres, aquesta sembla la font probable; i la Genealogia permet explicar per separat les dues solucions. Ara bé, si ens hi fixem, tampoc resulta tan clar que la Genealogia sigui la font en el cas de Corella, perquè el seu «féu creure» es relaciona amb el Commento («facto credere») o amb la seva traducció catalana («fet creure»), punt on Alegre té diu-li, Boccaccio dixit i Ovidi narrat. És a dir, d'una banda Corella i Alegre segueixen una mateixa referència però no tenen la mateixa oració («mal de la spantable mar» i «treball de la mar»), i de l’altra, Corella té «féu creure», relacionat amb el Commento, no amb Alegre. Curiosament, encara que la referència es trobi en Boccaccio, Alegre no la comenta a les seves Al-legories, potser perquè la mentida que Tereu dóna a la dona no demana ser comentada. En conclusió, casos com aquest no demostren una relació Corella-Alegre, però tampoc demostren el contrari. Per això cal classificar-los com a equipol-lents.

En els casos següents succeeix el mateix. Hi trobem una referència comuna Corella-Alegre, de redactat divergent i present en altres punts de la tradició. Són de nou lectures que cal tractar com a equipol-lents als dos autors:

4. Ovidi: om.; Bonsignori: om.; Genealogia: [Procne] pullo in habitu (Gen. IX.8, Zaccaria I998: 912); Parlament de Corella: [Procne] cuberta de negre (Martos 2001a: 281-282); Commento ai Trionfi: om.; Transformacions: [Procne] ab negra vestidura (TF VI.5; Bescós 2OI9b: 24I); Al·legories: [Procne] vestida de negre (AL VI.5).

5. Ovidi: om.; Del Virgilio: om.; Bonsignori: om.; Genealogia: Qui [Cèfal] cum se mercatorem finxisset [...] in mercatorem se transtulit (Gen. XIII.65); Commento ai Trionfi: [Cèfal] prese habito di mercatante (BNF ms. Italien 552, f. 5 ${ }^{\text {Ir) }}$; Comentarials Trionfi: [Cèfal] prengué àbit de mercader

I5. És la versió catalana anònima de finals de segle XV del comentari d'Ilicino als Trionfi de Petrarca.

I6. És la versió castellana del comentari d'Ilicino als Trionfi de Petrarca, traduïda al castellà al segle XVı per Antonio de Obregón.

I7. Podria tractar-se d'una deformació del gemitus factos ('uns fets lamentables'), de la variant del còdex Rhen. de l'edició de Jahn (I832: 382). Aquesta variant podria haver evolucionat a una versió propera a la del Comentario d’Obregón («muerta en el camino»), d’on s’hauria inferit que mor pel viatge marítim, ja que en l'episodi es comenta més d’una vegada que el viatge o camino és marítim. Una altra explicació possible a aquesta innovació podria respondre a la imaginació d'algun comentarista: atès que Filomela es transforma en oreneta, podria haver confós o interpretat una per l'altra, potser associant el viatge de la noia al vol migratori d'aquestes aus per damunt les ones, entre Àfrica i Europa. Agraeixo a Jaume Torró les apreciacions en relació a aquestes suposicions. 
(Recio 2009: 132); Comentario a los Trionfi: [Cèfal] tomó hábito de mercader (Recio 20I2: 93); Parlament de Corella: de mercader era [Cèfal] vera ymage (Martos 200Ia: 24I); Transformacions: [Cèfal] transformat en figura de un estrany mercader (TF VII.8; Bescós 2OIg: 264). ${ }^{18}$

6. Ovidi: om.; Bonsignori: om.; Genealogia: [Ulisses] in domum Lycomedis [...] se mercatorem finxisset (Gen. XII.52, Zaccaria 1998: г2I6); Commento ai Trionfi: [Ulisses] non conoscendolo si finse essere merchatante (BNF ms. Italien 552, f. 229r); Comentari als Trionfi: Ulixes lavòs no conexent-lo, ffengí ésser mercader (Recio 2009: 5O7); Comentario a los Trionfi: [Ulisses] desconoscido en forma de mercader (Recio 2OI2: 290); Al-legories: del palau de Licomedes (AL XIII.I) + [Ulisses] fengint-se mercader (aL XII.8); Raonament de Corella: [Jo (Ulisses)] fengint-me mercader [...] en la casa del rey Licomedes (Martos 200Ia: I32); Transformacions: [Jo (Ulisses)] fengint ésser mercader [...] en lo palàcio de Licomedes (TF XIII.2; Bescós 2OIgb: 367 ).

Com hem vist en el cas 3, aquestes coincidències són possibles a partir de la Genealogia de Boccaccio, que Alegre tradueix i refâ a les seves Al-legories, i que també es relaciona amb l'obra de Corella. ${ }^{19}$ A més, en alguns casos la referència també es troba en el Commento ai Trionfi de Petrarca de Bernardo Ilicino, relacionat amb la lectura de Petrarca feta per autors de temàtica sentimental com Corella i Alegre. ${ }^{20}$ És, doncs, informació divulgada que només permet demostrar que aquests textos s'insereixen en una mateixa tradició de comentari, traducció i adaptació literària de Les metamorfosis. Fixem-nos que en tots els casos la referència és comuna, però la forma del redactat és sempre divergent. És a dir, es tracta de la mateixa referència, però formulada diferentment: per exemple, en el cas 4 Corella té cuberta però en Alegre trobem vestida i vestidura.

L'últim cas que presentem en aquest apartat de lliçons equipol-lents és interessant, perquè permet entreveure un ancestre comú als dos testimonis de la Lamentació de Tisbe avui conservats $(X U)$ :

7. Ovidi: om.; Bonsignori: om.; Genealogia: om.; Commento ai Trionfi: [Semíramis] commisse lo scelerato incesto di Nino suo figliolo (BNF, ms. Italien 552, f. $5^{2 r}$ ); Comentari als Trionfi: [Semíramis] cometé lo celerat incest de Nino, son fill (Recio 2009: 134); Comentario a los Trionfi: [Semíramis] cometió el nefando pecado de incesto con Nino su hijo (Recio 20I2: 94); Lamentació de Tisbe de Corella: [Semíramis] mare de [...]no (Juno XU) (Annicchiarico 2016: 2I); Transformacions: [Semíramis] mare del noble Nino (TF IV.2; Bescós 2OIgb: I75); Al·legories: om.

Com s'observa, la referència comuna entre Alegre i Corella («mare de [...]no» / «mare del noble Nino») pot explicar-se per separat, ja que la informació es troba en els comentaris. En relació a la transmissió textual de l'obra de Corella ens trobem davant d'un error conjuntiu de la seva tradició manuscrita, ja que la lliçó de $X U$ («mare de Juno»: Rea) no té cap sentit en el text perquè l'aposició es refereix a Semíramis, a qui s'atribueix l'incest amb el seu fill Ninus, que alguns autors antics donen com a marit i amant. ${ }^{21}$ La lliçó correcta es troba a les Transformacions (Nino). No és possible que les Lamentacions reportessin Juno en aquest punt, sinó que es tracta d'un error present en els dos testimonis de les Lamentacions. Aquest cas demostra que, si aquí cal parlar d'algun punt

I8. Torró (ı999: ı92, n. I8) assenyala la glossa de Servi a l’Eneida com a origen d'aquesta variació de Corella.

I9. Per a la relació entre Corella i Boccaccio vegeu Martos (200Ib).

2O. Per al comentari d’Ilicino i la seva relació amb Alegre, vegeu Bescós (20I4).

2I. A les escasses fonts que informen d'aquesta reina llegendària, Semíramis apareix com a esposa del rei Ninus. Així ho transmet Diodor Sícul (II.I-22), que els fa pares d’un noi anomenat Nínia. És probable que, en algun punt de la transmissió, la semblança entre els noms Ninus i Nínia hagi provocat l'assimilació a un únic personatge Ninus (Nino), i per això aquest apareix com a fill i amant de Semíramis. Per al procés de desmitificació d'aquest episodi dins la tradició catalana, incloses les Transformacions, vegeu Compagna (2OI2). 
de contacte entre l'obra de Corella i les Transformacions, aquest ha de ser anterior a la còpia dels dos testimonis que preserven l'obra del valencià. El copista d'un dels dos testimonis, o un ancestre comú a $X U$, copià per error Juno, per confusió de la lectura del grup ni en iu, escrit en minúscula, canvi afavorit per la naturalesa de lectio facilior del nom, més famós i divulgat que Ninus. Alegre, en canvi, té la lliçó correcta. L'adjectivació noble Nino que trobem a les Transformacions respon a un recurs freqüent d'Alegre, marca del seu estil de prosa. ${ }^{22}$

En resum, els casos equipol-lents tant poden provenir d'una filiació textual entre Corella i Alegre com explicar-se per separat a partir d'un mateix estil de prosa i de la tradició de l'Ovidi medieval. Per tant, només demostren que tant Corella com Alegre escriuen, en un mateix moment històric i en un estil comú, obres de temàtica ovidiana i mitològica a partir de manuscrits, comentaris i glosses que s'emparenten i que tenen referències comunes no presents en l'original primer d'Ovidi.

\section{${ }_{3}$ Passatges comuns entre Corella i Alegre}

A més dels casos equipol-lents anteriors, hi ha una sèrie de passatges inequívocament comuns. Es tracta de casos coincidents en els quals els dos autors no poden haver arribat a un text determinat sense que les seves obres es relacionin. Aquests casos demostren la filiació entre l'obra de Corella i la d'Alegre. Ara bé, convé tenir present que, a priori, la filiació entre dos testimonis d'un text (o dues obres amb el mateix text) es pot explicar de tres maneres possibles: ( $a$ ) del testimoni I al 2 (de Corella a Alegre); (b) d'un testimoni 3 a I-2 (d'un ancestre comú a Corella i Alegre); i (c) d'un testimoni 3 a un dels dos testimonis ( I o 2), i d'aquí a l'altre (d'un ancestre a Corella, i de Corella a Alegre). D'entrada, només podem donar més validesa a una o altra possibilitat a partir d'elements contextuals, literaris i històrics, qüestions naturalment cabdals, però en el cas de la relació CorellaAlegre, sobre la qual encara hi ha tantes ombres, cal assignar, d'entrada, la mateixa possibilitat a totes tres opcions. Els passatges inequívocament comuns entre Corella i Alegre, tot i no il-luminar sobre com es produeix la filiació, demostren que efectivament entre Corella i Alegre hi ha una filiació que es donà d'una d'aquestes tres maneres.

Aquests passatges comuns es poden classificar en dos grups: els que s'expliquen per una addició en relació als originals, i els que responen a alteració de l'ordre, a substitució o a omissió dels originals traduïts o adaptats en un punt determinat. En el primer cas hi ha aquells passatges comuns Corella-Alegre que no hem localitzat a cap punt de la tradició textual d'Ovidi i que són, doncs, afegitons respecte dels originals. En el segon cas hi ha aquells passatges que es corresponen amb algun punt dels originals.

\section{I. Afegitons i addicions}

Si bé la intenció d'Alegre a les Transformacions és depurar les versions anteriors, millorar la traducció poc artitzada de Bonsignori i oferir, com sosté, la primera versió al vulgar de l’original llatí digna d'aquest nom - això és, un text que presenti el poema d'Ovidi sense resums, amplificacions ni comentaris, i que respongui a la concepció estilística de la seva prosa d'art -, el barceloní sovint recorre a mètodes de traducció que critica. ${ }^{23}$ Té una concepció força clara del text que vol facturar, i això el porta a prendre’s certes llibertats amb l’original a partir d’una delimitació no clara,

22. Per a l'ús de l'adjectivació com a recurs estilístic en Alegre, vegeu especialment Bescós (20I9a: 64-8I).

23. En relació al mètode d’Alegre a les Transformacions, vegeu especialment Bescós (20Igb). 
pretesament conscient i volguda, de la frontera entre l'Ovidi traduït i l'Ovidi com a material per a les seves obres sentimentals. D’aquí que els afegitons i amplificacions sentimentals siguin molt freqüents al llarg de les Transformacions. Es tracta d'un dels trets que defineixen la traducció, i poden anar d'unes quantes paraules a oracions senceres com la següent:

Ovidi: om.; Bonsignori: om.; Transformacions: y tots en la gran sala esperaven Filomena, detenint lo temps ab aquelles raons més plasents que podían, quant isqué la senyora en orde per lo viatge que fer desliberave (TF VI.5; Bescós 2OIgb: 237).

A les Transformacions, a més, hi ha una correspondència entre l'aparició d'afegitons i l'interès per la sentimentalitat de l'episodi traduït. Així, no és estrany trobar un dels afegitons més extensos a l'episodi altament emotiu de Píram i Tisbe (TF IV.2; Bescós 2oIgb: I76):

Y replicava ella:

- Tostemps é hoït dir que dues voluntats a una fi girades les coses molt dífícils y quasi impossibles acaben sens treball. No cansem de pansar remeys al present mal.

-Ha, Tisbe! -deya Píramo-. Totes les nits me fugen seguint tal pensament y remey no sé veure sens perill de la vida y tacha de la honra.

E axí, sovint, acostats a la creta, detenían lo dia ab semblants parlaments. Y alenant la un a l'encontre de l'altre, ab calor de inflamat alè, descobria quascú ço que·n secret portava; girats a la paret, sovint axí li dèyan.

Alguns d'aquests afegitons es relacionen inequívocament amb l'obra de Corella. Comencem per un cas de l'episodi de Narcís: ${ }^{24}$

8. Ovidi: om.; Bonsignori: om.; Comentario a los Trionfi: om.; Lamentació de Narcís de Corella: curant poch obehir a Venus, en la apartada religió de Diana (la partida e la religiosa diana $X$ ), ab gran supèrbia me defenia de les enamorades fleixes de Cupido (Annicchiarico 20I6: I7); Transformacions: retret en los boscatges per fugir a les dones, seguí la vida de Diana (TF III.5; Bescós 2Orgb: I6I).

Aquest passatge apareix en el mateix punt narratiu de la història a la Lamentació de Narcís i a les Transformacions, i no es troba ni en Ovidi, ni en Bonsignori, ni en el comentari de Petrarca. No només el «de Diana» final es comú a Alegre i Corella (es tracta, en el fons, d'una divinitat que retrobem a les obres sentimentals d'Alegre per designar la castedat), sinó que la informació reportada en els dos passatges és la mateixa. Ara bé, Corella mostra un detallisme mitològic (la pugna Venus i Diana) absent en Alegre. Com dèiem, casos d'aquesta tipologia permeten traçar una relació textual, tot i que en aquest cas hi hagi clares divergències entre els dos autors. El fet que aquesta informació no aparegui a cap altra font, i que es trobi en el mateix punt de la història, permet sostenir la relació. Naturalment, que el passatge corellà, en comparació amb el d’Alegre, resulti formalment en una amplificatio mitològica de la dicotomia Venus (amor) - Diana (castedat), no indica que Corella amplifiqui el passatge, ja que el més natural, des del punt de vista històric, és veure-hi una simplificació d'Alegre. En definitiva, podem demostrar que el text és inequívocament comú; però textualment no podem demostrar d'on parteix aquest text.

Hi ha casos més representatius a l'episodi de Píram i Tisbe, on Alegre, per l’interès de la història, es pren més llibertats que en altres punts:

9. Ovidi: om.; Bonsignori: om.; Genealogia: om.; Commento ai Trionfi: om.; Lamentació de Tisbe

24. En relació a aquest passatge, vegeu Pellissa (2Org: 2O-2I). 
de Corella: sovint alçava (alçant $X$ ) los ulls a Febo. E paria’m los seus cavalls ésser tant canssats que tenien lo dia en major espay del acostumat (Annicchiarico 20I6: 23); Transformacions: inculpant ab murmur los cavalls del gran Febo, perquè ab cansat pas duraven tant lo dia (TF IV.2; Bescós 2OIgb: I77); Al.legories: om.

Aquest afegitó no és present ni en Ovidi ni en Bonsignori - les fonts habituals d'Alegre -, ni tampoc a Genealogia - Al-legories, fonts secundàries usades per Alegre a la seva traducció. Les variacions d'Alegre respecte de Corella s'expliquen per procediments habituals a les Transformacions: el gran respon a l'adjectivació de substantius, i el cansat pas a un estilema propi d'Alegre. ${ }^{25}$ De nou, el text corellà resulta en una amplificatio si el comparem amb el text de les Transformacions.

Io. Ovidi: om.; Bonsignori: om.; Genealogia: om.; Commento ai Trionfi: om.; Lamentació de Tisbede Corella: $\mathrm{E}$ ab aquests treballs passàvem nostra vida enamorada, fins que un jorn (tro atant que hun jorn X) (Annicchiarico 20I6: 22); Transformacions: Aquesta fon la vida dels dos enamorats y durà per gran temps, fins que.s seguí un dia (TF IV.2; Bescós 2OI9: I76); Al·legories: om.

En aquest cas, les variants s'expliquen pel canvi en la veu del narrador: en Corella és Tisbe, i en Alegre és una de les Minèiades, narradora de tot l'episodi a l'original d'Ovidi. Aquesta diferència comporta canvis, com el «nostra vida enamorada», en Alegre «vida dels dos enamorats», i «passàvem nostra vida», en Alegre «y durà [la vida] per gran temps». El final «fins que.s seguí un dia» és semblant al «fins que un jorn» de la variant conservada al Cançoner de Maians $(U) .{ }^{26}$

Hem detectat encara un últim afegitó comú; en aquest cas, a l'episodi de Mirra. És un afegitó especial perquè retrobem el passatge al Tirant:

II. Ovidi: o [...] felicem coniuge matrem! ('oh, mare, feliç amb l'espòs!', Met. X.422); Bonsignori: O beata madre mia, come hai sì bel marito (Ardissino 200r: 490); Genealogia: om.; Commento ai Trionfi: om.; Lamentació de Mirra de Corella: Sies çerta persona al món benaventurada sia no estime (no crech persona al mon beneventurada sia $X$ ), sinó sola ma mare, que té Sínaras per marit. E parlar més avant no·m conssentí vergonya. Mas ab dolorosos sospirs manifestava lo cubert seny de mes paraules, tant que entés la sàvia dida lo gran desorde de ma benvolença, e ab suaus paraules assajava si de tant desllimitat desig me poguera retraure (Annicchiarico 20I6: I4-I5); Transformacions (Mirra): O, com és benaventurada ma mare, pus és muller de Cínaras! -no consentint-li de més dir la vergonya (TF X.6; Bescós 20Igb: 320); Al-legories: om.; Tirant lo Blanch: Parlant no em consentí vergonya, la qual sovint d'extrema amor és enemiga, però ab dolorosos sospirs manifestava lo cobert seny de mes paraules. E en lo gran desorde de ma benvolença (rèplica de la princesa a Tirant, cap. 246 ; Hauf-Escartí I992: 2,540$).{ }^{27}$

\subsection{Alteracions, substitucions i omissions dels originals}

Però no tots els passatges comuns Corella-Alegre es mostren com un afegitó, sinó que en alguns casos es relacionen amb els originals, sobretot amb el llatí d'Ovidi, com al passatge següent de

25. En relació a l'ús estilístic de l’adjectivació en Alegre, vegeu Bescós (2019a: 64-8I).

26. Atesa la concordança del text d'Alegre amb una variant del Cançoner de Maians $(U)$, convé recordar que les Transformacions es relacionen amb un estadi anterior dels manuscrits que preserven l'obra de Corella, com hem demostrat a l'apartat anterior a partir del cas «mare del noble Nino».

27. El cas també es troba a Pellissa (2Or9: 29), sense indicar la seva coincidència amb el passatge del Tirant. 
l’episodi de Píram i Tisbe:

I2. Ovidi: fissus erat tenui rima, quam duxerat olim | cum fieret, paries domui communis utrique. | id vitium nulli per saecula longa notatum ('la paret comuna d'una i altra casa tenia una obertura, una esquerda petita que s'havia fet en altre temps quan es construïa; aquest defecte no vist per ningú al llarg dels segles', Met. IV.65-7); Bonsignori: E fra lle case loro era uno muro, el quale era communo dell'una e dell'altra casa, in lo quale era una rottura, la quale non era anco per altro stata veduta che per costoro (Ardissino 200I: 2I6); Genealogia: om.; Commento ai Trionfi: fero costoro [Píram i Tisbe] in nel murro intermezo una piccola rimula (BNF ms. Italien, f. 39r); Comentari als Trionfi: [Píram i Tisbe] feren en lo mur o paret que la una e l'altra casa partia una xiqueta fenella (Recio 2009: IO9); Comentario a los Trionfi: [Píram i Tisbe] hizieron un agujero por una pared que passava de la una casa a la otra (Recio 20I2: 80); Lamentació de Tisbe de Corella: una secreta (streta $X$ ) fenella en aquella paret que nostres cases departia; la qual, fins en aquell temps, no era estada vista (Annicchiarico 2OI6: 2I-22); Transformacions (Pírami Tisbe): En la paret comuna qui les cases partia era una fenella, la qual en tants cents anys no era stada vista (TF IV.2; Bescós 2OIgb: I76); Al·legories: om.

Resulta evident la semblança entre els textos catalans, especialment per l'expressió «paret que nostres cases departia» / "paret comuna qui les cases partia», en llatí «paries domui communis utrique», certament divers, i en Bonsignori «uno muro, el quale era communo dell'una e dell'altra casa», també divergent respecte de Corella-Alegre. A més de la paret, es descriu l'esquerda per on els dos joves parlen l'un amb l'altre. En Ovidi no hi ha l'oració adjectiva que trobem en Alegre (la qual...), que prové de Bonsignori (la quale...) i que també trobem a Corella (la qual...), sinó que l'adjectiva llatina del quam va referida al moment en què es va produir l'esquerda, no al fet que no hagués estat vista durant molt de temps. L'esquerda (rima en Ovidi i rottura en Bonsignori) és fenella tant en Alegre com en Corella, i també es relaciona el comú «no era stada vista», que sembla remuntar més aviat a Bonsignori, que introdueix el sentit de la vista («non era anco per altro stata veduta»), en llatí «nulli ... notatum» ('no notada per ningú'). També sembla comuna a Alegre i Corella l'eliminació del llatí nulli ('per ningú'). El valencià i el català construeixen la passiva sense l'agent, que sí que té el text llatí. La diferència «fins en aquell temps» / «en tants cents anys» s'explica per influència del llatí «per saecula longa» i per la voluntat de correcció i depuració d'Alegre. Curiosament, l'adjectivació secreta ( $\operatorname{streta} X$ ) de Corella no és present en Alegre, tot i que un tret de les Transformacions sigui l'adjectivació com a recurs estilístic.

A més de l'episodi de Píram i Tisbe, l’episodi de Mirra també presenta passatges inequívocament comuns: ${ }^{28}$

13. Ovidi: gentes tamen esse feruntur, | in quibus et nato genetrix et nata parenti | iungitur ('No obstant, es diu que hi ha pobles on la mare s'uneix al fill i la filla al pare', Met. X.33--333); Bonsignori: om.; Lamentació de Mirra de Corella: E més, he hoït dir en una part del món habitar gents que no han vergonya (en una part ... vergonya om. X) que una sola sia mare e germana de sos fills (Annicchiarico 20I6: I2); Transformacions: y més que tot açò me escusa de culpa si ver és lo que he hoït dir: en una part del món és consentit al pare de casar ab la filla y ab lo fill la mare (TF X.6; Bescós 20I9b: 3I8).

En aquest cas, l'oració «he hoït dir en una part del món» és comuna a Corella i Alegre. ${ }^{29}$ Part d'aquesta oració no apareix copiada al Jardinet d'orats $(X)$ i només es troba en el Cançoner de

28. Els dos casos següents també es troben a Pellissa (2019: 28-29), analitzats diferentment.

29. L'expressió una part del món d'Alegre es correspon al llatí gentes ('pobles'), i la retrobem (deguna part del món, TF XII.2; Bescós 2OIgb: 349) per traduir totum in orbem ('per tot el món'), i encara part del món (TF XV.4; Bescós 2orgb: 4I4) tradueix el més semblant 'pars mundi'. 
Maians (U), però recordem que, si cal parlar d'una influència directa de Corella en Alegre, aquesta es dóna amb un ancestre anterior dels testimonis que preserven l'obra del valencià, com demostra el cas anterior «mare del noble Nino». En qualsevol cas, resulta evident que els textos de Corella i Alegre estan relacionats.

Aquesta no és l'única lectura d'aquest tipus que trobem a l'episodi de Mirra:

I4. Ovidi: perque novem noctes Venerem tactusque viriles | in vetitis numerant ('durant nou nits consideren prohibida Venus i el contacte amb els homes', X.434-435); Bonsignori: ciascuna persona se dovesse guardare de non toccare sua donna per spazio de nove dì e nove notti (Ardissino 200r: 490); Lamentació de Mirra de Corella: E, per fer més acceptables lurs sacrifiçis, apartant-se de la religió de Venus, leixaven (leixaven om. $U$ : apartaven se de lur religio de venus e leixaven $X$ ) per nou dies los lits frets a sos marits ( $U$, f. 53r; Annicchiarico 20I6: I5); Transformacions: e per nou continuades nits dexaven las mullers lo lit de lurs marits (TF X.6; Bescós 2OIgb: 32I).

Com s'observa, l'oració de les Transformacions «per nou continuades nits dexaven las mullers lo lit de lurs marits» és comuna a «per nou dies los lits frets a sos marits», formulada diferentment en llatí. De nou trobem una coincidència que relaciona les Transformacions només amb un dels còdexs de les Lamentacions, en aquest cas el Jardinet d'orats $(X)$. És evident que el text d'Alegre i el de Corella $(X)$ es relacionen, especialment pels mots lits frets / lit i sos marits / lurs marits.

A l'episodi de Mirra encara trobem un altre passatge comú: ${ }^{30}$

15. Ovidi: at Cinyras, quem copia digna procorum | quid faciat dubitare facit, scitatur ab ipsa, | nominibus dictis, cuius velit esse mariti. | illa silet primo patriisque in vultibus haerens | aestuat et tepido suffundit lumina rore. | virginei Cinyras haec credens esse timoris | flere vetat siccatque genas atque oscula iungit. | Myrrha datis nimium gaudet consultaque, qualem | optet habere virum «similem tibi» dixit ('Però Cíniras, a qui l'honorable abundància de pretendents fa dubtar què pot fer, li pregunta a ella mateixa, després de dir-li els noms, qui voldria que fos el seu marit. Ella primer calla i, clavant els seus ulls en el rostre del pare, s'encén i els banya amb una rosada tèbia. Cíniras, creient que aquestes coses son pròpies de la timidesa d'una donzella, li prohibeix plorar i li eixuga les galtes i li fa petons; Mirra gaudeix més del compte amb aquests petons, i preguntada sobre quin marit voldria tenir, va dir: «un de semblant a tu»", Met. X.36I-4); Bonsignori: uno dì el padre la domandò ch’ella li dovesse dire chi li piacea che fosse suo marito e nominòlinne molti. Mirra non respuse e basciando el padre cominciò a piangere; Cinnara pensava ch'ella piangese per paura della sua verginità e perciò cominciò a llosengarla, domandandole quale ella voleva per marito. Respuse Mirra: «Io voria solo te» (Ardissino 20OI: 489); Genealogia: om.; Commento ai Trionfi: om.; Lamentació de Mirra de Corella: «O Mirra, puix la tua edat de bells néts me fa promesa, digues-me, a qui seràs contenta liurar los teus honrats tàlems». Mas, yo callant, per la mia cara de vergonya colorada cahien làgremes semblants a fonts corrents sobre fresches roses. E penssava Sínaras yo ploràs per temor de entrar en la més plaent que perillosa batalla, la qual les honestes donzelles mostren tembre; e, lohant la mia vergonya, ab les seus mans sechava les abundants fonts de mes làgremes. E deÿa que no era maravella la nova terra refusàs lo primer aradre. Demanant-me altra vegada qual me paria digne de possehir (levar $X)$ ma castedat en líçit matrimoni, responguí: «Yo desige (vull $X$ ) marit que en res a vós (a vos en res $X$ ) no dessemble» (Annicchiarico 20I6: II); Transformacions: un jorn, entrant lo rey dintre lo seu retret, ab prechs solicitave la sua pensa duptosa que de tants nobles elegís un marit, demanant-li sovint qui la tenia en dupte, recordant-li los noms de cada un de aquells per escusar en ella del nomenar vergonya. Callà primer per bon espay aquella, y aprés, ferm mirant en la cara del pare, començà a plorar. Cregué Cínaras ésser aquests senyals de temerosa verge y diu-li que no plore, axuga-li les galtes y los ulls ab les mans, besa-la en la boca (de què no poch Mirra se alegrà), torna-la a pregar que li digue sens dupte quin

30. Aquest cas també es troba en Pellissa (20I9: 29), analitzat des d'una altra perspectiva.

Magnificat CLM 7, 202O, IO3-I34. ISSN 2386-8295 
marit desijave, y entra la instància de tants prechs hoí ab veu molt baxa la resposta següent: «Senyor, yo volria marit que en res a vós no desemblàs» (TF X.6, Mirra, 2019b: 319); Al·legories: om.

En primer lloc, cal notar que, en Ovidi, l'element central de l'episodi és la percepció del pare Cíniras que el comportament de Mirra és degut a la seva timidesa, pròpia de donzella, que Ovidi reitera amb illa silet, aestuat, virginei timoris i «tepido suffundit lumina rore». Aquest domini de la timidesa es troba subvertit en el text de Corella, on es desplaça en benefici de la percepció paterna que la noia tem per preservar la seva virginitat, que Corella reforça amb afegits no presents en Ovidi («temor de entrar en la més plaent que perillosa batalla»o «E deÿa que no era maravella la nova terra refusàs lo primer aradre»). Aquesta variació en la naturalesa del temor o preocupació de la noia pot ser una innovació de Corella, però no resulta l'única explicació si ens fixem, per exemple, en el text de Bonsignori. L'italià tradueix el virginei timoris ('temor o timidesa de donzella') per paura della sua verginità. No hem trobat cap variant en el text llatí del tipus virginitatis ('de la virginitat') en comptes de virginei ('de la donzella'), mot que d'altra banda tindria problemes de mètrica en el vers ovidià. Amb tot, l'al-legorització i interpretació de personatges mitològics en relació a aspectes morals, com aquí la castedat, és freqüent en comentaris, compendis i traduccions ovidianes del període.$^{3}$ Es pot tractar, doncs, d'una interpretació per separat de Corella i Bonsignori, remuntar a una glossa, o remetre a la tradició medieval d'Ovidi; però, com veurem, no és l'única coincidència entre l’italià i el valencià. Alegre elimina aquesta subversió i amplificació present en Corella i té com a nucli narratiu la timidesa i vergonya de Mirra, com trobem en Ovidi ('timidesa de donzella'). A la taula següent hi ha l'esquema narratiu de l'episodi en Ovidi, Bonsignori, Corella i Alegre, i els punts de contacte i divergències.

\begin{tabular}{|l|l|l|l|}
\hline Ovidi & Bonsignori & Corella & Alegre \\
\hline Cíniras pregunta pel marit & Sí & Sí & Sí \\
\hline Diu el nom dels pretendents & No & No & Sí \\
\hline Silenci de Mirra & Sí & Sí & Sí \\
\hline $\begin{array}{l}\text { Mirra clava els ulls en el rostre } \\
\text { del pare }\end{array}$ & Cíniras besa Mirra & No & Sí \\
\hline $\begin{array}{l}\text { Mirra s'encén de vergonya i es } \\
\text { ruboritza }\end{array}$ & Mirra plora & Sí, i plora & Mirra plora \\
\hline $\begin{array}{l}\text { Cíniras atribueix la vergonya } \\
\text { a la timidesa/por de Mirra }\end{array}$ & $\begin{array}{l}\text { Cíniras atribueix el } \\
\text { plor a la por de la noia } \\
\text { per la seva virginitat }\end{array}$ & $\begin{array}{l}\text { Cíniras atribueix el } \\
\text { plor a la por de la noia } \\
\text { per la seva virginitat }\end{array}$ & $\begin{array}{l}\text { Cíniras atribueix } \\
\text { la vergonya a la } \\
\text { iimidesa/por de } \\
\text { Mirra }\end{array}$ \\
\hline Cíniras prohibeix plorar a Mirra & No & No & Sí \\
\hline Eixuga les galtes de la noia & No & Sí & Sí \\
\hline Cíniras besa Mirra & $\begin{array}{l}\text { Cíniras pregunta per } \\
\text { segona vegada }\end{array}$ & $\begin{array}{l}\text { Cíniras pregunta per } \\
\text { segona vegada }\end{array}$ & $\begin{array}{l}\text { Sí, i Cíniras pregunta } \\
\text { per segona vegada }\end{array}$ \\
\hline Mirra gaudeix dels besos & No & No & Sí \\
\hline Mirra finalment parla & Mirra respon & Mirra respon & Mirra respon \\
\hline
\end{tabular}

Taula I. El diàleg entre Mirra i Cíniras

3․ En relació a la lectura al-legòrica dels personatges de Dafne i Mirra, vegeu el cas núm. i6. 
Com s'observa, a més de desplaçar el motiu de l'actitud de Mirra, tal vegada per una mala interpretació del llatí virginei, a l'original llatí la noia, després de ser preguntada pel pare una sola vegada, calla fins que al final diu la frase que tanca l'episodi. Però Bonsignori, potser en considerar que Mirra retarda massa la seva resposta, introdueix una repetició de la pregunta de Cíniras, com també fan Corella i Alegre, i que potser explicaria que el llatí dixit sigui respuse en italià, responguí en Corella i resposta en Alegre. Si bé hom pot traduir el dixere per 'respondre', especialment en un diàleg, és cert que responguí i resposta van en paral-lel a l'aparició en els textos de la insistència paterna. Hi ha, doncs, dos elements que relacionen el text de Bonsignori amb el de Corella: la reiteració de la pregunta de Cíniras i el temor de Mirra per la seva virginitat com a motor narratiu. Si ens fixem en el text Corella-Alegre, el llatí similem tibi, solo te en Bonsignori, té la mateixa formulació: no dessemble i no desemblàs. A més, a la resposta final de Mirra ambdós hi emplacen, dins l'estil directe, part de l'oració de l'estil indirecte anterior, rèplica molt més breu en Bonsignori i Ovidi. Ens trobem, efectivament, davant del mateix text entre Corella i Alegre, el qual, com hem vist, podria néixer en els dos autors del creuament d'Ovidi amb Bonsignori. ${ }^{32}$ Potser caldria remuntar a Corella el no desemblàs de les Transformacions, i per context així ho creuríem, però no ho podem demostrar, perquè casos comuns com aquest només indiquen la relació textual entre Corella i Alegre, no la manera com aquesta es produeix.

\section{Un passatge comú significatiu entre Corella i Alegre}

$\mathrm{P}$ er últim, hi ha un passatge comú Corella-Alegre que, a banda de confirmar la filiació entre els dos autors, informa sobre com aquesta es produeix. El passatge es troba en els episodis de Dafne i de Mirra: 33

I6. Ovidi (Dafne): saepe pater dixit «generum mihi, filia, debes»; | saepe pater dixit «debes mihi, nata, nepotes». | illa velut crimen taedas exosa iugales | pulchra verecundo suffunditur ora rubore, | inque patris blandis haerens cervice lacertis | «da mihi perpetua, genitor carissime» dixit, | «virginitate frui; dedit hoc pater ante Dianae». | ille quidem obsequitur, sed te decor iste quod optas | esse vetat, votoque tuo tua forma repugnat ('sovint el pare li deia: «em deus un gendre, filla»; sovint el pare li deia: «em deus néts, filla». A ella, que avorria les torxes conjugals com un crim, a causa del seu pudor se li havia enrojolat el bell rostre, i en els braços tendres del seu pare, abraçada al seu coll, li va dir: «Pare estimat, deixa'm gaudir d'una virginitat perpètua: això li va concedir a Diana el seu pare». Ell, en efecte, es mostra complaent, però el teu propi encant prohibeix allò que demanes, i la teva bellesa impedeix el teu desig», Met. I.48I-9); Ovidi (Mirra): Undique lecti | te cupiunt proceres, totoque oriente iuventus | ad thalami certamen adest. ex omnibus unum | elige, Myrrha, virum -dum ne sit in omnibus unus. | illa quidem sentit foedoque repugnat amori, | et secum «quo mente feror? quid molior?» inquit ('et pretenen nobles escollits d'arreu, la joventut de tot l'orient arriba per rivalitzar pels teus tàlems. Elegeix, Mirra, d'entre tots un marit, mentre no sigui aquest [Cíniras]. Ella, en efecte, n'és conscient i lluita contra un amor tan vergonyós, i es diu: «On em porten els meus sentiments? Què tramo?», Met. X.3I5-3I8); Bonsignori (Dafne): E spesse volte li dicea el padre: «Io te maritarò, onde io averò genero e molti nepoti». Ed ella ciò schifava sì come odiosa del matrimonio e deventava roscia e vergognavase con molta temenza, e mettease fra lle braccia del padre dicendo: «Pregote, padre mio, che tu me lassi

32. Com que Alegre tradueix tenint davant el text de Bonsignori, això podria explicar el volria de les Transformacions (voria en Bonsignori), tot i que aquest verb també pot provenir del subjuntiu desideratiu optet.

33. Això no vol dir que la relació que aquest cas il-lumina es pugui extrapolar a la resta de passatges detectats. Com que analitzem obres i no còpies, les conclusions poden només ser vàlides en aquest punt. 
usar perpetual virginitade, e questo tu el de' fare, con ciò sia cosa che Diana anco ricevé questa grazia dal padre, adunque bene lo poi fare a me». El padre respondea e dicea: «Io te concederia questo, ma la tua bellezza non concede che tu si' senza marito (amore $P$ ) » (Ardissino 200I: 122, Dafne); Bonsignori (Mirra): Essendo custei in tanta miseria, invaghita sceleramente del padre, in quel tempo Cinnarra era da molti pregato che lla volevano per moglie, ed uno dì el padre la domandò ch'ella li dovesse dire chi li piacea che fosse suo marito e nominòlinne molti. Mirra non respuse e basciando el padre cominciò a piangere; Cinnara pensava ch'ella piangese per paura della sua verginità e perciò cominciò a llosengarla, domandandole quale ella voleva per marito. Respuse Mirra: «lo voria solo te» (Ardissino 200г: 489); Genealogia: om.; Commento ai Trionfi: om.; Lamentació de Mirra de Corella: [Cíniras diu:] «O, Mirra, puix [I] la tua edat de bells néts me fa promesa $(+[2]$ e la tua bellesa contrasta als frets vots de diana $X$, Annicchiarico 20I6: 25), digues-me, [3] a qui seràs contenta liurar los teus honrats tàlems» (Annicchiarico 20I6: II); Transformacions (Dafne): Quantes vegades li dix son pare: «Cara filla, [I] la tua edat me és deutora de néts. E per ço, si a tu plau, de tants nobles desijant ton acost [3] elegeix un ab qui benaventuradament fines ton viure». E ella, com a un leig crim avorrint lo matrimonial jou, tenyia per vergonya de rossa color lo tendre cuyro de la sua bella cara, e ab los estesos braços afalagant abraçava son pare, ab tremolosa veu dient-li: «Si en la reverència vostre, senyor pare, mos prechs troben algun loch, no·m sia per vós negada la virginitat poder tot lo temps de ma vida honrar, cosa ja obtenguda per Diana de son pare». A qui lo antich riu, responent, deya: «No per \{zbis $d\}$ desig de desviar ton pler m'estich de consentir al que demanes, [2] mes la tua excel-lent bellesa obvia a tant frets vots» (TF I.8; Bescós 2019b: IO2); Transformacions (Mirra): vegeu cas I5; Al-legories: om.

Com s'observa, podem traçar un mateix text entre la Lamentació de Mirra de Corella i l'episodi de Dafne de les Transformacions. Les oracions «la tua edat me és deutora de néts» $\mathrm{i}$ «la tua edat de bells néts me fa promesa» ho demostren, ja que en llatí trobem «debes mihi, nata, nepotes» ('filla, em déus néts'), molt diferent, i amb una formulació encara més divergent en Bonsignori («averò genero e molti nepoti»). En conseqüència, també podem relacionar les oracions «la tua excel-lent bellesa obvia a tant frets vots» $\mathrm{i}$ «la tua bellesa contrasta als frets vots de Diana», que, tot i ser més semblants al llatí 'votoque tuo tua forma repugnat» i a l'italià «ma la tua bellezza non concede che tu si' senza marito (amore $P$ )», i per tant ser possibles per separat, es poden establir com a text comú per la proximitat amb el primer cas. Així, en aquests dos punts, numerats com a [I] i [2] respectivament, Corella i Alegre transmeten un mateix text.

Les variacions entre Corella i Alegre responen a l'adjectivació dels mots bellesa i néts, al canvi llatinitzant del verb contrasta en obvia per part d'Alegre, i a l'eliminació del sintagma de Diana, present en Corella. En el cas [2], el català comú vots depèn del llatí voto de l'episodi de Dafne, no present en italià, però tant Corella com Alegre posen aquest [2] com a estil directe del diàleg parefilla, cosa que no trobem en Ovidi, però sí en Bonsignori. En Alegre, el [2] té un inici semblant (mes la tua) a Bonsignori (ma la tua), mentre que Corella té e la tua. Així, mentre que [I] es mostra com una traducció amb amplificació d'Ovidi, el [2], com succeeix en el cas I5, potser remet a un creuament d'Ovidi amb Bonsignori.

Ara bé, el que crida l'atenció d'aquest passatge és la seva localització. Corella posa el parlament en boca de Cíniras, pare de Mirra (Met. X); però Alegre, i Ovidi i Bonsignori el posen en boca de Peneu, pare de Dafne (Met. I). Tal com hem indicat, les semblances no són fruit de la casualitat, sinó que es tracta del mateix text. Però per què en Corella el passatge es troba dislocat? L'explicació, cal cercar-la en el tipus de diàleg: una conversa pare-filla (Peneu-Dafne i Cíniras-Mirra) on el pare demana a la filla que es casi. Dafne rebutja el matrimoni perquè vol seguir l'exemple de Diana (castedat autèntica), com s'especifica en Ovidi uns versos abans, però Mirra no vol casar-se 
perquè està enamorada del seu pare Cíniras (falsa castedat), amb qui precisament manté el diàleg. ${ }^{34}$ L'assimilació entre castedat autèntica (Dafne, Diana) i falsa (Mirra) ha de ser atractiva per als escriptors de literatura sentimental, perquè relaciona la castedat de la dama amb la falsedat, tòpic recurrent d'aquests autors i nucli narratiu tant de la Faula com de la Tragèdia de Caldesa. Aquest sembla un bon motiu perquè en Corella Cíniras parli com Peneu, confonent una amb altra història.

Si ens fixem ara en les dues oracions numerades com a [3], divergents entre Alegre («de tants nobles [...] elegeix un ab qui benaventuradament fines ton viure») i Corella («a qui seràs contenta liurar los teus honrats tàlems»), aquestes es relacionen, en els dos autors però per separat, amb l'episodi de Mirra d’Ovidi, en cap cas amb el de Dafne. En llatí, a la súplica inicial de Cíniras llegim «ex omnibus unum elige», relacionat amb l'oració d'Alegre («de tants nobles [...] elegeix un»), no present en Corella. Però en el valencià llegim tàlems, relacionat amb el llatí thalami de la mateixa súplica de Cíniras en Ovidi, no present en Alegre. Per acabar de complicar la trama, tant en Corella com en Alegre s'entreveu, més dubtosament, el piacea de l'episodi de Mirra de Bonsignori («seràs contenta» en Corella i benaventuradament en Alegre), matís no present a la resta de fonts. Com hem vist, en el [2] semblen confluir Bonsignori amb Ovidi, com en el cas I5; el mateix podria passar, doncs, en aquest [3].

En resum, [I] i [2] són punts comuns Corella-Alegre que remeten a l'episodi de Dafne dels originals, i les dues oracions [3], divergents entre si, es relacionen per separat amb l'episodi de Mirra. Si descartem que Corella prengui el passatge d'Alegre i que les oracions divergents [3] responguin a la mà dels copistes, aquest cas, com la resta de lectures comunes, té dues explicacions possibles:

I. Alegre pren el passatge de la Lamentació de Mirra. Perquè això es doni, Corella ha hagut d'adaptar l'episodi de Dafne d'Ovidi a la seva Lamentació de Mirra, tot assimilant el diàleg Dafne-Peneu i el de Cíniras-Mirra. Alegre, traduint l'episodi de Dafne del llatí i de l’italià de Bonsignori (potser amb Corella com a font secundària), recorda la Mirra de Corella (o la té al davant), la copia parcialment, però retornant-la al seu lloc original, l'episodi de Dafne. Després, consulta l'episodi de Mirra d'Ovidi per contrastar-lo amb el que ha trobat en Corella i afegeix, a partir del llatí, una oració de l'episodi de Mirra per completar la seva traducció del diàleg Peneu-Dafne, tot substituint el [3] de Corella, que ja provenia de l'episodi de Mirra, pel [3] que trobem a les Transformacions, també de l'episodi de Mirra.

\section{Corella i Alegre recorren a un text anterior. Un text anterior sobre Dafne, potser per la}

34. L’assimilació de Dafne amb la castedat, ja present en Ovidi («nec quid Hymen, quid amor, quid sint conubia curat», Met. I.480), resulta en una interpretació del mite àmpliament difosa: (a) Myth. Vat. («Illa [Daphne], advocato padre, ut virginitati opem ferret», II.23); (b) el comentari de Servi a l'Eneida («quae [Daphne] aspernata viro iungi semper venatibus operam dabat», II.5I3); (c) l'Ovide moralisé (JJe n’ai cure de mariage | ans vuel garder mon pucelage: | vierge sui et vierge serai; | ja pour ma biauté nel lerai», I.2857-2860). A l'Ovide moralisé(I.322I-3247), a més, s’assimila Dafne i Apol·lo a la Verge Maria i Jesús, i potser la unió Dafne-Mirra no s’allunya d’aquest text, atesa l’assimiliació Mirra-Verge Maria i Adonis-Crist que també hi llegim («La mirre amere signifie | Nostre mere, sainte Marie. | La sainte, la vierge pucele, | Qui de Dieu fu fille et ancele, | Qui tant fu bele et delitable | Et gracieuse et amiable, | Que de mains homes fu requise, | Mes tant fu ardaument esprise | De l'amour Dieu, cui fille elle iere, | Onc ne vault en nulle maniere | Metre son penser ne sa cure | En amer nulle creature [...] Nasqui li douz, li delitables, | Li savoureuz, li amiables | En qui toute biautez habonde, | Adonin, li sires dou monde, | Li sauvierres et li garans | Qui tout delivra ses parans | Et de reprouche et de pechiez», X.3750-376ı i X.3794-380o). Aquesta assimiliació entre Mirra i la Verge pot tenir l'origen en l'aparició de l'arbre de la mirra en la vida de Crist (Mt 2,II; Mc I5,23 i Jn I9,39-4O). En resum, la interpretació Mirra-Verge i Dafne-Verge potser explica la nostra assimilació Mirra-Dafne, un sincretisme que, a diferència del que trobem en aquestes fonts, pot tenir com a finalitat la difamació de la castedat. 
contraposició entre les figures de Dafne (castedat autèntica) i Mirra (falsa castedat), ha assimilat els diàlegs Peneu-Dafne i Cíniras-Mirra (D+M, en endavant), potser amb l'interès d'amplificar la relació entre aquests personatges i poder-los usar literàriament. Corella ha traslladat aquest text a l'episodi de Mirra i ha adaptat el [3] a partir d'Ovidi. Alegre, en canvi, ha trobat D+M en un text sobre Dafne i l'ha conservat en la seva traducció de Dafne. Alegre, o bé ha substituït el punt [3] recorrent a un altre passatge original de Mirra o, més plausiblement, el [3] d’Alegre resulta l'oració present a $\mathrm{D}+\mathrm{M}$.

D’entrada, a totes dues opcions, tant Alegre com Corella transmeten aquesta assimilació dels diàlegs de Dafne i Mirra. Però hi ha una diferència: la primera opció implica una factura corellana i un emplaçament de D+M en un episodi de Mirra, mentre que la segona fa dependre l'assimilació d'un ancestre compartit entre Corella i Alegre, suposadament un text sobre Dafne. Cal considerar, en primer lloc, que el diàleg assimilat, en origen, sembla pertànyer més aviat a un episodi de Dafne que no a un de Mirra. Certament el diàleg conté més elements, i més significatius, de l’original de Dafne. Per exemple, els punts comuns Corella-Alegre [I] i [2] pertanyen a Dafne, mentre que només els divergents [3] i la localització en Corella es relacionen amb Mirra. A més, l’interès de l'assimilació Dafne-Mirra és la descripció de la castedat autèntica (Dafne) com a falsa (Mirra), no a la inversa, i això funciona naturalment dins un episodi de Dafne. També, si el diàleg es troba en un episodi de Dafne és Corella qui el desplaça, però si remet al de Mirra, Alegre fa aquesta operació, i convé recordar que Corella fa una adaptació, més flexible en relació als originals, mentre que Alegre, per bé que amb excepcions, tradueix d'una manera força propera als originals. En aquest sentit, la primera opció encara presenta un altre inconvenient: la baixa probabilitat que els textos de Dafne en llatí o italià, que són els que segueix Alegre a les Transformacions, li recordin la Mirra de Corella, on es troben adaptats, perquè el llatí i l'italià són divergents, en més d’un aspecte, de la seva adaptació corellana. De fet, que Alegre pensi en la Mirra de Corella quan tradueix Dafne resulta més plausible a partir de l'ancestre, perquè aquest text i Corella han de tenir, aquí sí, oracions semblants, i per tant, l'ancestre pot alhora recordar-li el text del valencià i ser llegit per Alegre en traduir Dafne, si l'ancestre, com hem comentat, té el diàleg assimilat en un text sobre Dafne. ${ }^{35}$

Si ens fixem ara en els dos casos [3], divergents entre Corella i Alegre, ambdós són de l'episodi de Mirra. Segons la primera hipòtesi, Alegre substitueix el [3] de Corella, que prové de l'episodi de Mirra, per un nou [3], extret per Alegre també de l'episodi de Mirra. Això implica que tant Corella com Alegre han de consultar per separat l'episodi de Mirra d'Ovidi. No resulta gens estrany que Corella el consulti, perquè està adaptant la Mirra de Les metamorfosis, però és més complicat explicar els motius d'Alegre, que es troba traduint un altre episodi. Aquests dos casos [3] encara presenten un altre inconvenient: per què Alegre decideix substituir el [3] de Corella per un nou [3]? Per dissimular la dependència de Corella? Perquè ha imitat Corella de memòria i el reescriu tal com el recorda, i potser, atès que no el té a mà, ha de recórrer a l'episodi de Mirra d'Ovidi? Podria ser, però cal tenir present que a les dues oracions [3] sembla intuir-se el piacea de Bonsignori («seràs contenta» en Corella i benaventuradament en Alegre), matís no present a la resta de fonts, és a dir, són potser oracions relacionades, cosa que també pot contradir la idea de substitució per part d’Alegre. La segona opció, en canvi, permet explicar el [3] de Corella per una innovació del valencià, tot conservant el piacea en el seu «seràs contenta», i alhora associar el [3] d'Alegre a la lectura de l'ancestre $\mathrm{D}+\mathrm{M}$, que naturalment conserva restes del piacea de Bonsignori en el

\section{benaventuradament.}

35. És en aquest punt on també caldria considerar una combinació d’opcions, això és, la presència de l'ancestre compartit entre Corella i Alegre, i alhora una posterior consulta, per part d’Alegre, del text corellà. 
Com s'observa, no podem descartar cap de les dues opcions, però sí valorar quina és més factible. Contextualment, la influència corellana en Alegre resulta la proposta més plausible; però no amb els textos a la mà, on es complica. La presència de l'ancestre, en canvi, permetria explicar els textos sense inconvenients; però té objeccions contextuals, perquè matisaria la influència corellana en Alegre, i potser també en algun passatge de Martorell. Amb tot, ens sembla significatiu i rellevant que la substitució del cas [3] per part d'Alegre, conseqüència inevitable si considerem la primera hipòtesi, resulti inexplicablement un acte sense gaire sentit, lluny del mètode que segueix a la seva traducció. Així mateix, la primera hipòtesi fa igualment difícils d'explicar les motivacions d'una eventual assimilació D+M per part de Corella (seguint aquesta opció, caldria assignar l'assimilació a Corella). En canvi, un ancestre comú amb el diàleg assimilat D+M, construït a partir d'Ovidi i Bonsignori - un text que no és ni el que trobem en Alegre, tal com el tenim a les Transformacions, ni el que trobem en Corella; com a mínim no el text de les dues versions d'aquesta Lamentació que preservem - permet una explicació d'aquests textos en consonància amb les motivacions tant d’Alegre com de Corella. I, com hem indicat, això ens sembla rellevant, especialment perquè la resta de lectures comunes analitzades en els casos anteriors no informen sobre la relació entre els textos dels nostres autors, només poden demostrar que en efecte hi ha una relació.

\section{${ }_{5}$ Conclusions}

El punt de partida d'aquest estudi ha estat determinar si resultava plausible que algun d'aquests casos es relacionés amb un ancestre compartit entre Alegre i Corella avui no preservat. Cap dels casos exposats contradiu aquesta opció; en canvi, des d'un punt de vista textual, el cas i6 potser fa més viable que, com a mínim aquí, Alegre i Corella consultin un ancestre compartit. Per tant, la hipòtesi exposada al principi del treball resulta plausible. Ara bé, amb la informació i textos que preservem, no podem determinar quina obra caldria situar com a ancestre. La versió perduda de Pinós esdevé una identificació força temptadora, especialment per la relació entre alguns elements analitzats i Bonsignori, segons Alegre el text que segueix Pinós, i pel vincle històric entre Alegre, Corella i Pinós que exposem a l’Annex. Però l'ancestre podria no ser estrictament un text, sinó una fusió més o menys lúdica que circulés en certs ambients (probablement cortesans). Fins i tot podria respondre al mestratge de Dela Mirambella o a l'impuls i guia de Pere Torroella, com a mínim en relació a Alegre. I tampoc podem descartar que l'ancestre fos en realitat un estadi molt primerenc de les Lamentacions de Corella que no tenim, o encara la versió castellana perduda que Alegre diu conèixer.

L'admiració d'Alegre per Joan Roís de Corella, la dependència detectada en obres com la Faula, el fet que Alegre és més jove que Corella, i que el valencià és un autor consagrat, no ens poden dur a enfocar només les concomitàncies entre Alegre i Corella com una influència del valencià. Ens resulta fâcil d'imaginar Alegre incorporant, segons el seu gust, passatges de Corella a les Transformacions, i això ens resulta fâcil perquè Alegre ho fa a la Faula, on pren el tema i elements de l'obra de la Tragèdia de Caldesa; però aquesta interpretació obvia un fet important. Certament, autors com Alegre i Martorell recorren a Corella com a font per a la seva obra, però les Transformacions són una traducció, és a dir, un text que, a més de relacionar-se amb l'obra de Corella, i precisament perquè s'hi relaciona, pot connectar-se també amb les fonts de Corella. La poderosa imatge literària del valencià és tan present en l'obra d'Alegre com en el seu procedir literari, però entre les Transformacions i la Faula hi ha una diferència fonamental: la naturalesa diversa d'un i altre text. En veure en aquests passatges una influència directa de les Lamentacions, ¿pot ser que estiguem traslladant l'admiració d'Alegre per Corella, demostrada en textos com la 
Faula, a les Transformacions? Alegre ha llegit Corella, Bonsignori i Pinós: no pot haver identificat, per exemple, en Pinós passatges de Corella que deu tenir ben gravats a la memòria? És més: no podria saber-ho fins i tot abans de llegir Pinós, i haver-hi precisament recorregut per l'admiració per Corella, creient que podria imitar-ne millor la prosa si realitzava un treball amb els textos amb què Corella efectua els seus exercicis gramaticals i retòrics? La imitatio auctoris no consisteix només a cercar passatges de l'autor admirat, sinó a exercitar, entendre i assimilar el seu complex món literari; i una via per assolir-ho, en el cas d'Alegre, és l'exercitació amb el text d'Ovidi. No podem dubtar de la influència de Corella en Alegre, però limitar-la als textos preservats, per si sol, pot no ser suficient per explicar tots els passatges comuns exposats, especialment si hi ha un vincle històric entre Pinós, Corella i Alegre, tal com veurem a l'Annex.

A les Transformacions, Alegre ens adverteix que busca corregir, depurar i millorar la tradició de l'Ovidi medieval; i per fer-ho, mira de mantenir-se fidel al text llatí. Ara bé, en tot moment exercita la seva prosa d'art i exhibeix el seu domini (fictici o real) del tema amorós, sigui a través de l'afegitó sentimental o de la inclusió de jocs de naturalesa literària, com l'assimilació de Dafne i Mirra, que pot recollir de Corella, d'una tradició cortesana avui perduda o d'alguna versió primerenca de Les metamorfosis. 


\section{Obres citades}

Alcina, Juan Francisco, I998. 'El poeta como dios: la poética de Landino en España (de Francesc Alegre a Alfonso de Carvallo)', Salina, I2: 40-49

Alegre, Francesc, I 494. Els quinze libres de Transformacions del poeta Ovidi (Barcelona: Impremta de Pere Miquel) $\langle$ https: / / cataleg.bnc.cat/record=b2225607 $>$

Annicchiarico, Annamaria, 20I6. 'Joan Roís de Corella, Lamentació de Mirra, de Narciso,

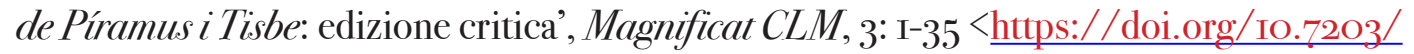
MCLM.3.8I32>

Ardissino, Erminia (ed.). 200I. Giovanni Bonsignori da Città di Castello Ovidio Metamorphoseos Vulgare (Bologna: Commissione per i Testi di Lingua)

Badia, Lola. I993. Tradició i modernitat als segles XIV i XV: estudis de cultura literària i lectures d'Ausiàs March (Barcelona: Publicacions de l’Abadia de Montserrat; València: Institut Universitari de Filologia Valenciana)

Bescós, Pere. 2007. 'Humanisme i traducció catalana durant la segona meitat del segle XV: Ferran Valentí, Arnau d'Alfarràs, Francesc Alegre i Aleix de Barcelona' (unpublished doctoral dissertation, Universitat Pompeu Fabra) <http://hdl.handle.net/IO230/I268 $>$

Bescós, Pere. 20II. 'Francesc Alegre: La primera guerra púnica, I472: estudi i edició crítica' (unpublished doctoral thesis, Universitat Pompeu Fabra) $\langle\underline{\text { http: } / / \text { hdl.handle.net/Io803 } / 3 \mathrm{I} 878}\rangle$

Bescós, Pere, 20I3. 'Los cavallers a fealtat covida: fortitudo i sapientia cavalleresques en la traducció del De bello Punico de Francesc Alegre', Els Marges, Iог: IO-3о

Bescós, Pere, 20I4. 'Comentari i formació literària en Francesc Alegre: Ovidi i Bernardo Ilicino', Llengua \& Literatura, 24: 33-53 〈https://doi.org/IO.2436/20.2502.0I.67>

Bescós, Pere (ed.). 20rga. Francesc Alegre Obres menors (Santa Barbara, CA: Publications of eHumanista) $<$ https://tinyurl.com/sezqgzw $>$

Bescós, Pere (ed.). 2orgb. Publi Ovidi Nasó, Les metamorfosis. Versió catalana del segle XV de Francesc Alegre (Santa Barbara, CA: Publications of eHumanista) <https://tinyurl.com/ $\underline{\mathrm{u} 3 \mathrm{Od} 2 \mathrm{e} 8}>$

Bescós, Pere. 2020. 'De Las metamorfosis de Ovidio a las Transformacions de Francesc Alegre', en Actas del VII Congreso Internacional de La SEMYR, 2018, ed. by Pedro Cátedra (Salamanca: Universidad de Salamanca)

Boer, Cornelis de (ed.). I9I5. Ovide moralisé: poème du commencement du quatorzième siècle, 2 vols (Amsterdam: J. Müller) <http://go.uv.es/3NXHoYP>

Bofarull, Manuel de, I864. Colección de documentos inéditos del archivo general de la Corona de Aragón (Barcelona: Impremta ACA), XXVI $<\underline{\text { http://go.uv.es/odXXWjỵ }>}$

Carbonell, Jordi, I955-56. 'Sobre la correspondència literària entre Roís de Corella i el príncep de Viana', Estudis Romànics, 5: I27-I39 < $\underline{\text { http://go.uv.es/3vtXhI }>}$

Cingolani, Stefano M., I998. 'Joan Roís de Corella i els límits de la literatura', Caplletra, 24: I3-24 $<\underline{\text { http://go.uv.es/EFazusL }>}$

Compagna, Anna M., 20I2. Piramo e Tisbe nelle Metamorfosi di Ovidio tradotte e commentate da 
Francesc Alegre (1494), in Filologia e Linguistica: studi in onore di Anna Cornagliotti, ed. by L. Bellone et alii (Alessandria: Edizioni dell'Orso), pp. 449-458

Compagna, Anna M., 20I4. Giasone e Medea in Francesc Alegre (Barcellona 1494) e in Joan Roís de Corella (Gandia? 435 - València 1497), in Filologia e letteratura: studiofferti a Carmelo Zilli, ed. by Angelo Chielli and Leonardo Terrusi (Bari: Cacucci)

Cuadrada, Coral; Duran, Daniel; Martínez-Giralt, Alejandro. 20I8. Elfons Llull de l'Arxiu dels Marquesos de Santa Maria de Barberà (Tarragona: Publicacions de la Universitat Rovira i Virgili) <https://doi.org/IO.I7345/9788484246862>

Duran, Eulàlia; Vilallonga, Mariàngela (ed.). r99o. Antonio Beccadelli El Panormita Dels fets e dits del gran rey Alfonso: versió catalana del segle XV de Jordi de Centelles (Barcelona: Editorial Barcino)

Ferraú, Giacomo. 1982. La cultura in Sicilia nel Quattrocento (Roma: De Luca)

Ghisalberti, Fausto. I933. Giovanni del Virgilio espositore delle 'Metamorfosi'(Firenze: Leo S. Olschki)

Gómez Moreno, Ángel; Kerkhof, Maximilian P.A.M. (ed.). I988. Íñigo López de Mendoza Marqués de Santillana Obras Completas (Barcelona: Planeta)

Gómez, Francesc J. 20I5: 'Joan Roís de Corella. Proses d'inspiració clàssica i cortesa', en Història de la literatura catalana, ed. Àlex Broch (Barcelona: Enciclopèdia Catalana; Editorial Barcino; Ajuntament de Barcelona), III: Literatura medieval (III): segle XV, ed. by Lola Badia, 222-24I

Guthmüller, Bodo. 1997. Mito, poesia, arte: saggi sulla tradizione ovidiana nel Rinascimento (Roma: Bulzoni)

Hauf, Albert G.; Escartí, Vicent J. (ed.). I992. Joanot Martorell (Martí Joan de Galba?) Tirant lo Blanch, 2 vols (València: Generalitat Valenciana)

Jahn, Johannes C. (ed.). I832. P. Ovidï Nasonis quae supersunt Opera Omnia (Leipzig: Frid. Christ. Guil. Vogelii), II.I: P. Ovidii Nasonis Metamorphoseon libri XV: libr. I-VII, I-475 < https:// tinyurl.com/ychgtnfd $>$

Martí, Sadurní, 1997. 'El cançoner del marquès de Barberà ( $\left.S^{\prime} / B M i\right)$ : descripció codicològica', Boletín Bibliográfico de la Asociación Hispánica de Literatura Medieval, II: 463-502 <https:// $\underline{\text { tinyurl.com/wdqgozd> }}$

Martos, Josep Lluís (ed.). 2oora. Les proses mitològiques de Joan Roís de Corella (València: Institut Interuniversitari de Filologia Valenciana; Barcelona: Publicacions de l'Abadia de Montserrat)

Martos, Josep Lluís, 20oib. 'Boccaccio y Roís de Corella: las Genealogiae deorum', Cuadernos de Filología Italiana, Extra 3: 535-557 $\left\langle\underline{\text { http://go.uv.es/ } / \mathrm{V}_{3} 16 x_{4} \mathrm{G}}>\right.$

Martos, Josep Lluís, 20I5. 'Joan Roís de Corella: vida i formació', en Història de la literatura catalana, ed. by Àlex Broch (Barcelona: Enciclopèdia Catalana; Editorial Barcino; Ajuntament de Barcelona), III: Literatura medieval (III): segle XV, ed. Lola Badia, 2II-22I

Moncunill, Noemí, 20I5. 'Las Metamorfosis de Ovidio traducidas por Francesc Alegre (I494): algunas observaciones sobre la problemática de las fuentes', in Miscellanea Latina, ed by M. T. Muñoz García de Iturrospe and L. Carrasco Reija (Madrid: Sociedad de Estudios Latinos; Universidad Complutense de Madrid), pp. I45 ${ }^{-\mathrm{I}} 5^{\mathrm{I}}$

Pellissa, Gemma, 20I7. 'The Italian sources of the Catalan translation of Ovid's Metamorphoses by 
Francesc Alegre (I5th c.)', Zeitschrift für romanische Philologie, I33.2: 443-47I < $\underline{\text { https://doi. }}$ org/IO.I5I5/zrp-2OI7-OO22 $>$

Pellissa, Gemma, 20I9. 'Algunes dades sobre la influència de les proses mitològiques de Corella a les Transformacions de Francesc Alegre', Caplletra, 66: 15-32 <https://doi.org/I0.7203/ caplletra.66.I350I>

Pujol, Josep (ed.). 2or8. Publi Ovidi Nasó Heroides: traducció catalana medieval de Guillem Nicolau, Els Nostres Clàssics-Autors Medievals, 37 (Barcelona: Editorial Barcino)

Quer, Pere. I988. Estudi sobre Francesc Alegre: dues obres inèdites, el Sermó de Amor i la Passió de Jesucrist (unpublished doctoral dissertation, Universitat Autònoma de Barcelona)

Recio, Roxana (ed.). 2009. Los 'Trionfi' de Petrarca comentados en catalán: una edición de los manuscritos 534 de la Biblioteca Nacional de París y del Ateneu de Barcelona, North Carolina Studies in the Romance Languages and Literatures, 293 (Chapel Hill: University of North Carolina Press)

Recio, Roxana (ed.). 20I2. Antonio de Obregón Francisco Petrarca, con los seys triunfos de toscano sacados en castellano, con el comento que sobrellos se hizo (Santa Barbara: Publications of eHumanista) $<$ http://go.uv.es/f7vEgtk $>$

Reginato, Irene, 20I8. 'La faula di Narciso nelle Transformacions di Francesc Alegre: studio comparatistico ed edizione del testo', Medioevi, 4: 209-237 $<$ https://tinyurl.com/swparqa $>$

Riquer, Martí de. I934. L'humanisme català: 1388-1494 (Barcelona: Editorial Barcino)

Riquer, Martí de. I964. Història de la literatura catalana: part antiga, 3 vols (Barcelona, Ariel)

Riquer, Martí de. I990. Aproximació al 'Tirant lo Blanc'(Barcelona: Quaderns Crema)

Rodríguez Risquete, Francisco, 2002. 'Del cercle literari del Príncep de Viana i unes poesies satíriques del Cançoner de Saragossa', Estudi General: Revista de la Facultat de Lletres de la Universitat de Girona, 22: 365-391

Rodríguez Risquete, Francisco (ed.). 20II. Pere Torroella, Obra completa, 2 vols, Els Nostres Clàssics B, 3I-32 (Barcelona: Editorial Barcino)

Rubio Vela, Agustín, 20I9. 'Sobre Berenguer Mercader, anfitrión del Parlament de Joan Roís de Corella, y demás contertulios', Scripta, I4: I-33 <https://doi.org/IO.7203/SCRIPTA.I4.I6357>

Sobrequés, Santiago. 1973. La Guerra civil catalana del segle Xv: estudis sobre la crisi social $i$ econòmica de la Baixa Edat Mitjana, 2 vols (Barcelona: Edicions 62)

Tarrant, Richard J. (ed.). 2004. P. Ovidii Nasonis Metamorphoses (Oxford: Oxford University Press)

Torró, Jaume, r994. «Officium poetae est fingere»: Francesc Alegre i la Faula de Neptuno $i$ Dyana', in Intel-lectuals i escriptors a la Baixa Edat Mitjana, ed. Lola Badia and Albert Soler (Barcelona: Curial; Publicacions de l'Abadia de Montserrat), 22I-24I

Torró, Jaume (ed.). I996. Romeu Llull Obra completa, Els Nostres Clàssics A, I35 (Barcelona: Editorial Barcino)

Torró, Jaume, I999. 'Ausiàs March no va viure en temps d'Ovidi', in Estudis de Filologia Catalana: dotze anys de l'Institut de Llengua i Cultura Catalanes Secció Francesc Eiximenis, ed. Pep Valsalobre and August Rafanell (Barcelona: Publicacions de l’Abadia de Montserrat), I75-I99

Torró, Jaume, 200I. 'Una cort a Barcelona per a la literatura del segle Xv', Revista de Catalunya, 
I63: 97-I24

Torró, Jaume, 2002. 'Joanot Martorell, escrivà de ració', LAAvenç, 273: I2-I8 < $\underline{\text { http://go.uv.es/ }}$ $\underline{\mathrm{PlqBSp} 4}>$

Torró, Jaume, 2OII. 'Els darrers anys de Joanot Martorell, o en defensa del Tirant, la novel·la cavalleresca i la cort', in La novel.la de Joanot Martorell i l'Europa del segle XV, ed. by Ricard Bellveser, 2 vols (València: Institució Alfons el Magnànim), pp. 573-584

Torró, Jaume, 20I2. 'Només hi ha un Joan Martorell documentat amb el nom de Joanot: resposta i correcció a Agustín Rubio Vela amb unes notes sobre Manuel de Rajadell', Tirant: Butlletí

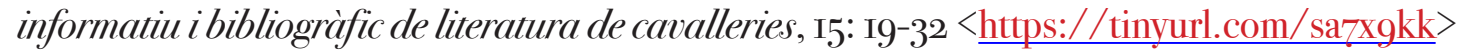

Wittlin, Curt, r993. 'Joan Roís de Corella: introducció a una concordança de les seves obres', in Actes del Novè Col-loqui de l'AILLC, ed. Rafael Alemany, Antoni Ferrando and Lluís B. Meseguer (Barcelona: Publicacions de l'Abadia de Montserrat; València: Universitats d'Alacant, València i Jaume I), I: 327-366

Wittlin, Curt, 1997. 'La Biblis, Mirra i Santa Anna de Joan Roís de Corella: Traduccions modulades, amplificades i adaptades', Anuari de l'Agrupació Borrianenca de Cultura, 8: I75-I89 < $\underline{\text { http:// }}$ go.uv.es/vFxf $7 \mathrm{w}_{3}>$

Zaccaria, Vittorio (ed.). I998. Tutte le opere di Giovanni Boccaccio (Milano: Mondadori), VII-VIII: Genealogie deorum gentilium, De montibus, silvis, fontibus, Lacubus, fluminibus, stagnis seu paludibus, de diversis nominibus maris 


\section{Annex. El vincle històric possible: la cort del príncep Carles d'Aragó}

$\mathrm{T}$ ot i no poder assegurar que l'ancestre que s'entreveu sigui el text de Pinós, hem cregut oportú mostrar a mode d'annex la plausibilitat històrica del vincle entre Corella, Alegre i Francesc de Pinós (ca.I4I6 - ca.I475), camarlenc, ambaixador i membre de la cort del príncep de Viana. La versió parcial de Pinós és l'única anterior a Alegre que coneixem, i a més, representa una interpretació del poeta romà, mestre de l'amor, feta per un membre de la cort del príncep de Viana. Pot connectar, doncs, amb els interessos literaris de tota una generació d'escriptors com Corella o Alegre.

En primer lloc, cal dir que dins l'ambient cortesà de Francesc de Pinós no hi ha rastres documentals de cap còdex de Les metamorfosis. Per exemple, en el testament del príncep Carles de Viana no hi consta cap exemplar d'Ovidi (Bofarull I864: III-230). Amb tot, es consigna un apartat d'objectes recobrats on s'han d'anar llistant aquells béns mobles del príncep que es troben en mans d'altres persones i que se li van retornant o que caldrà lliurar als marmessors del testament. Carles de Viana té una llibreria completa, amb volums d'Aristòtil, Sant Tomàs, un De officius de Ciceró, Sèneca, la seva traducció de les Ètiques, Bruni, Petrarca, Boeci, Plini, Plutarc, Dant, Flavi Josep, Isop, Palmieri, Egidi Romà, etc. No hi ha, però, cap volum d'Ovidi. El príncep també posseeix tapissos historiats amb els treballs d'Hèrcules o amb episodis del Roman de la Rose. En el testament tampoc trobem cap referència a la traducció italiana de Bonsignori, text utilitzat per Francesc de Pinós i per Alegre.

Ara bé, el fet de no trobar cap còdex d'Ovidi en aquest testament no impedeix la presència d'Ovidi a la cort del príncep, ni la presència de la traducció de Francesc de Pinós. Les dades que conservem sobre biblioteques catalanes del període mostren un Ovidi residual, en sintonia del que es desprèn de l'inventari del príncep, però el poeta romà apareix de manera continuada en la literatura catalana del període, com bé fa notar Pujol (2OI8: 73-74): ${ }^{36}$

Els rastres documentals són només una part d’una realitat més complexa, com ho demostra la presència continuada d'Ovidi en la literatura catalana. Eiximenis, Metge, Canals, Malla, l'anònim del Curial, March, Corella o Martorell poden citar Ovidi des de la seva experiència escolar de teòlegs, notaris o, simplement, laics amb formació gramatical i cortesana.

Ovidi és un autor citat, modulat i traduït amb més assiduïtat que no indiquen les restes documentals. Les adaptacions i traduccions no mostren una traducció completa de les seves obres, de l'estil de la que fa Alegre, sinó que parlem d'extractes o parts que tenen més interès, especialment en relació al discurs amorós de cort, que cal relacionar amb un grup de faules mitològiques molt presents entre els escriptors del XV. És probable que sigui en aquesta tradició on calgui situar la versió de Pinós. En canvi, la traducció de les Heroides de Guillem Nicolau i la de Les metamorfosis de Francesc Alegre responen a una voluntat diferent de presentació d'Ovidi; en el cas d'Alegre, una interpretació del de Sulmona altament mediatitzada per l'al-legorització de la Genealogia de Boccaccio, obra que Alegre adapta a les seves Al-legories. Les Heroides, retrats psicològics ovidians, són també presents a la sentimentalitat literària, i ja se situen a la cort a finals del segle XIII (Pujol 20I8: 24-32).

A banda d'aquestes disposicions, en el seu testament Carles d'Aragó ordena que es cancel-lin tots els deutes contrets amb mercaders (Bofarull ı864: Iı3). La família Alegre, mercaders influents, fou creditora del príncep fins l'any I460, quan Francesc Alegre pare es va negar a seguir-lo finançant

36. Sobre la presència d'Ovidi a les lletres catalanes, vegeu Badia (I993). 
perquè temia no cobrar. ${ }^{37}$ L'escriptor Francesc Alegre, doncs, és membre d'una important família de mercaders barcelonins prestadors de la casa reial. De Francesc de Pinós i de Joan Roís de Corella coneixem, millor o pitjor, l'abast de la seva relació amb la cort i el paper que hi jugaven. Els indicis sobre Francesc Alegre en aquest aspecte, com veurem tot seguit, porten a creure que la relació amb la cort fou més propera que no han demostrat les restes d'arxiu a dia d'avui. Ara com ara, la figura d'Alegre es perfila com la d'un escriptor format no lluny d'aquests ambients, cosa que explica les seves relacions posteriors, encara força desconegudes, amb la cort de Joan II, a qui Alegre dedica el Sermó d'amor. Com han mostrat Torró (200I) i Rodríguez Risquete (2OII: I.55), la figura de Torroella, més gran que no la de Francesc Alegre, serveix per resseguir l'evolució de les corts Trastàmara. Recordem que Francesc Alegre es relacionà epistolarment amb Torroella en el Debat sobre la figura d'Honor.

Si tornem ara als arxius, entre I458 i I460 Francesc Alegre pare esdevé, com dèiem, creditor a Sicília del príncep de Viana i del virrei de l'illa. ${ }^{38}$ Un document de I459 situa Francesc Alegre sènior a Palerm, just un any després de la mort del Magnànim, des d'on, segons els documents, dirigeix una gran quantitat de negocis. ${ }^{39}$ Recordem que del I $45^{8}$ al I459, el príncep de Viana i la seva cort, provinents de Nàpols, s'instal.len a Sicília. Com hem apuntat, en aquesta cort hi havia escriptors com Francesc de Pinós, Pere Torroella, i, com a mínim quan la cort es trobà a Catalunya, Joan Roís de Corella, «el más suficiente ante nuestra presencia», en paraules del príncep de Viana (Carbonell I955-56: І3г; Riquer I964: 3, 298). El debat entre Carles d'Aragó i Corella, d'on estan tretes aquestes paraules, s'ha situat en aquestes dates (Riquer 1990: 30I; Martos 20I5: 2I2) i, com la cita sembla indicar, tot apunta a un contacte proper, no a distància. Aquesta relació, amb les dades que tenim avui, s'hauria produït al Principat i no a Sicília, on els documents no situen Corella. ${ }^{40}$ Sigui com sigui, en els tres anys que van de la mort del rei Alfons a la mort de Carles d'Aragó, Corella manté un vincle estret amb el príncep i el seu cercle literari (Martos 2OI5: 2I2). Els personatges reals que, per exemple, apareixen en el Parlament en casa de Berenguer Mercader, constitueixen un cercle íntim que també es relaciona amb el príncep i el seu pare, Joan II. ${ }^{4}$ En el cercle literari de la cort també se situa l'escriptor Joanot Martorell..$^{22}$ El març de I464, Martorell empenyora a Martí Joan de Gualba el manuscrit del Tirant lo Blanch, obra on hi ha passatges provinents de les proses mitològiques de Corella. Aquestes proses s'han explicat com a obres de l'etapa formativa de l'autor («exercicis de retòrica», Wittlin I993: 338; Cingolani 1998). Durant aquesta etapa, Corella s'hauria servit de Les metamorfosis per practicar i conformar la seva prosa a través de l'amplificació i l'adaptació de mites ovidians, com una sort de praexercitamina. A les Transformacions trobem un exercici semblant, com mostren, per exemple, el recurs de l'afegitó i la concepció clara que té Alegre del text d'arribada que vol facturar, que es relaciona amb el model de prosa que pretén.

Una figura important de l'entorn del príncep és el procurador reial Giacomo Mirabella o Iacobo Dela Mirambella, important mestre de grec palermità que va formar, entre d'altres, l'humanista

37. L'escriptor i el seu pare tenen el mateix nom de pila, Francesc.

38. ACA: reg. 3.4I7, II de desembre de I $45^{8}$ (f. 57r), 4 de gener de I460 i I8 de gener de I 460 (ff. I39, I59v, I62r): tres ordres de pagament a la tresoreria de Palerm a favor de «Francesc Alegre, m. b., per diners prestats al rei» (apud Torró I994: 240). ASP CR, I9 de maig de I459 (ff. ıIO, I96v): Francesc Alegre, mercader de Barcelona, dóna crèdit al príncep de Viana (apud Torró I994: 240). ACA: Canc. reg. 3·480, 28 de maig de I460 (f. IOI) i 30 de juliol de I460 (f. I23v): Francesc Alegre dóna crèdit al virrei de Sicília (apud Torró I994: 240).

39. ACA, Canc. Reg. 3472, 9 de gener de I459: «in civitate Panormi dicti Regni Sicilie domum propiam tenentem et in eodem regno multa comercia mercanciarum et negocia gerentem» (apud Torró 1994: 229).

40. Per a la presència de Corella a la Catalunya vianista, vegeu la síntesi de Rodríguez Risquete (2002: 379).

4I. Martos (2OI5: 2I2). Per als personatges del Parlament, vegeu Rubio Vela (2OI9) i la síntesi de Gómez (2OI5).

42. Vegeu Torró (2OOI, 2002, 2OII i 2OI2). 
Luci Marineu Sícul (Torró I994 i 200I). A les Al-legories, Alegre sosté haver estat deixeble seu. 43 Dela Mirambella s'encarregava de recaptar fons per al rei i el príncep entre els mercaders catalans de Sicília (Torró I994: 240). Del I458 al I46o, els anys que la cort es troba a Sicília, les dades d'arxiu situen Francesc Alegre pare amb freqüència a Palerm, tot i que una cosa ben diferent és situar-hi l'escriptor, nascut cap al I $45^{2}$. Si aquell any l'escriptor es trobava a Palerm, l'arribada del príncep i la seva cort el degué impactar profundament. Si no hi era, l'impacte degué ser igualment important el I460, en entrar el príncep a Barcelona. Naturalment, aquests préstecs dels Alegre al príncep de Viana no indiquen un contacte proper i continuat amb la cort, encara menys per part d’un joveníssim Francesc Alegre; però Alegre, al capdavall, tingué com a preceptor el mestre Dela Mirambella, cortesà del príncep Carles. El primer contacte de què tenim constància entre Francesc Alegre pare i el mestre es dóna a Palerm el I459, però si tenim en compte l'edat de l'escriptor, aquesta sembla una data prematura. L'any I 459 el príncep i la cort, també Dela Mirambella, passen a Mallorca, on els Alegre tenen negocis, i finalment l’any I46o entren a Barcelona. Residís on residís el joveníssim escriptor, hagué de sentir-se estimulat pel contacte amb aquest ambient, i també el pare Francesc Alegre, que va voler educar el fill segons el que s'hi aprenia, amb la vista posada en el futur del fill i en el dels assumptes familiars. Aquest sembla el motiu per enviar-lo a escola amb el mestre Dela Mirambella, fos a Sicília o a Barcelona, on el mestre també es documenta de nou el iz $\mathrm{i}$ I8 de juny de I46I (Rodríguez Risquete 2OII: I, 72).

Així, educar el fill amb Dela Mirambella respon a la voluntat del pare d'acostar-lo aviat a l'exclusivitat de la cort. Com indica Tor ró (I994: 229), en aquesta etapa de formació hi podríem situar un primer contacte amb els textos de Bruni i Ovidi com a exercicis de tipus escolar. La història de la guerra púnica de Leonardo Bruni que Alegre tradueix té per escenari l’illa de Sicília, i convé recordar l'afició del Magnànim per Bruni, com testimonia Antonio Beccadelli (ı990: I89). També a Nàpols, entre el I457-58, el príncep Carles havia traduït al castellà la versió llatina de Bruni de l’Ètica d'Aristòtil. Atesa l'admiració per Bruni a la cort del Magnànim, no ens sembla casual que Romeu Llull copiés, quan residia a Nàpols, amb bella cal-ligrafia i filigranes pròpies de la Cancelleria, l’obra llatina de Leonardo Bruni De bello Gothorum (Torró I996: 2I). Torró ja intuí que Romeu Llull devia haver-se format a cort, i les troballes recents en arxius ho han confirmat, ja que el I $47^{2}$ està documentat com a majordom de l'infant Joan d'Aragó, fill de Ferran I de Nàpols i d'Isabel de Chiaramonte (Cuadrada et al. 20I8: 8o). D’Alegre, en canvi, de moment desconeixem l'abast exacte dels seus contactes a cort. En els dos casos, però, tenim una relació directa amb Pere Torroella, cortesà conegut i guia d'autors, potser, com en el cas d'Alegre, no relacionats directament amb l'entorn del príncep Carles, però amb tota seguretat propers a la cort i estimulats pel seu ambient. Leonardo Bruni té més presència a Nàpols que a Barcelona, i, tant si Alegre tradueix La primera guerra púnica a Sicília com a Barcelona, sembla haver-hi, en l'elecció de Bruni, un eco d'aquella cort napolitana, potser a través del mestre Dela Mirambella. Sigui com sigui, aquesta educació hauria donat a Francesc Alegre la formació necessària per relacionar-se literàriament amb escriptors d'aquest ambient, com Llull o Torroella, i fins i tot per acabar dedicant el Sermó a Joan II i les Transformacions a la infanta Joana d'Aragó. ${ }^{44}$

43. Per al fragment de les Transformacions on Alegre descriu Iacobo Dela Mirambella, vegeu Torró (I994: 227). Giacomo Ferraú (I982: 24) parla de la faceta de mestre de Iacobo Dela Mirambella: «di costui [Mirambella], al contrario del Naso, non si possiede documentazione di un suo insegnamento ufficiale nelle strutture cittadine, ma la sua competenza è attestata da una traduzione dell'isocrateo opuscolo A Nicocle, dedicata a Ferdinando il Catolico non ancora re di Aragona, ma già correggente di Sicilia (quindi tra il I468 e il I479), che rivela una buona conoscenza della lingua greca e una non spregevole capacità ed eleganza versoria. La lettera prefatoria insiste poi sui consueti concetti dell'esemplarità della speculazione classica nei confronti del principe moderno» (apud Torró 1994: 227).

44. A l'epíleg de les Transformacions de I494, Alegre menysprea la resta de literats barcelonins, fet que encaixa amb

Magnificat CLM 7, 2020, IO3-I34. ISSN 2386-8295 
Com hem avançat, a finals de I46o les vicissituds del conflicte entre el príncep de Viana i Joan II van provocar que Francesc Alegre pare es negués a seguir deixant diners a Carles de Viana, empresonat, perquè temia no recuperar-los. ${ }^{45}$ Francesc de Pinós va ser un dels tres ambaixadors designats immediatament per les corts per demanar l'alliberament del primogènit. Pinós va restar fidel a la causa antijoanista fins el I464, quan, després de ser empresonat acusat de conspirar contra Pere de Portugal, passà a les files de Joan II, que l'amnistià i li retornà les seves terres..$^{46}$ També per aquestes dates, Torroella gaudeix de nou de la protecció de Joan II, després d'un breu parèntesi en contra del rei. A més de la traducció parcial de Les metamorfosis d'Ovidi i d'una de les respostes dels Deseiximents contra Fals Amor, s’atribueix a Francesc de Pinós una Complanta per la mort del príncep Carles i la còpia del Cançoner del Marquès de Barberà $\left(S^{\prime}\right) .{ }^{47}$

En relació a la prosa que mostra Pinós als Deseiximents de Pou, aquesta no es relaciona directament amb la prosa d'art que trobem en Alegre i Corella, cosa que pot dificultar relacionar la seva versió amb l'ancestre comú Corella-Alegre. Però cal tenir present que, per exemple, en el Debat sobre la figura d'honor, Alegre tampoc recorre a aquest estil de prosa. La temàtica de la intervenció de Pinós als Deseiximents pot requerir un tipus de prosa divers que, com en el cas d’Alegre, és compatible amb un estil més artitzat per als temes mitològics i amorosos.

En aquests anys que els Alegre són prestadors del príncep de Viana (ho seguiran sent de Joan II), tots els seus contactes poden haver influït en el jove escriptor, atès que, per la formació amb Dela Mirambella, ha adquirit una educació emuladora del que ha copsat com a literatura cortesana. Això explica, per exemple, la dedicatòria de La primera guerra púnica, feta el juny de I472, en el context del setge de Barcelona (I47 I-72). Com hem mostrat amb anterioritat (Bescós 2OI3), el prefaci d'aquesta traducció es pot llegir com un consell de Francesc Alegre al cunyat Antoni de Vilatorta, membre important del bàndol antijoanista, ordenat cavaller pel príncep de Viana, a qui Alegre anima a posar fi a la resistència. Alegre no li adreça un text a l'atzar d'un autor qualsevol, sinó un text de Leonardo Bruni, un escriptor que, si Vilatorta no pot relacionar amb Alfons i amb Carles d'Aragó, i en el fons amb la seva causa, ben segur que ho pot fer Francesc Alegre per al cunyat.

una formació d'aquest tipus, més o menys cortesana i pretensiosa, que dóna la volada necessària per a una exclusivitat que es presumeix, relacionada amb ambients italians, i potser una mica fora de lloc després de la guerra civil, com es dedueix del to a la defensiva amb què Alegre escriu aquest epíleg.

45. ASP CR, 20 de desembre de I460 (ff. IIO, 296v): negativa de deixar diners al príncep Carles, perquè el príncep és a la presó (apud Torró I994: 229).

46. Vegeu Enciplopèdia Catalana, s.v. Francesc de Pinós: «Fou capità, per designació del Consell del Principat, de les tropes que l'acompanyaren de Tortosa a Barcelona el I462. Intervingué en les negociacions de la capitulació de Vilafranca; el mateix any Carles de Viana l'envià, amb Francí Desplà, prop del rei Lluís XI de França per tal d’obtenir l'aliança d'aquest. Quan esclatà la guerra continuà fidel a la causa de la generalitat de Catalunya. Durant el I462 formà part de l'estat major del capità de l'exèrcit de la generalitat, el comte Hug Roger III de Pallars, i participà en el setge de la Força de Girona i en les accions contra l'exèrcit francès. Fou nomenat capità de la flota del Principat i exercí missions de vigilància marítima durant el I463. Formà part del consell del conestable Pere de Portugal el I464»; vegeu també Sobrequés (I973: 2, 93-IOI).

47. Per a l'atribució del Cançoner del marquès de Barberà a Francesc de Pinós, vegeu Martí (i997: nota 29): «Com ja s'ha comentat en parlar dels aspectes codicològies, el cançoner de Barberà té tot l'aspecte de compilació inacabada (un 20\% del còdex és en blanc). ¿Quan es va interrompre la còpia? La peça més tardana de S és la poesia Los fats cruels per migà de Fortuna de Joan de Santcliment (datada per Riquer el novembre o desembre de I474). El cançoner es deixa de copiar, doncs, el I475, any en què tenim constància de la mort de Francesc de Pinós. La coincidència d’indicis, dates i ambients permetria d’hipotitzar, em sembla, que Francesc Galceran de Pinós és el compilador del Cançoner del marquès de Barberà. La via genealògica també apunta cap a ell: tot i les complexes derivacions del llinatge Pinós, la connexió entre Francesc Galceran de Pinós i el marquesat de Barberà és directa: Jeroni de Pinós-Santcliment (m. I584), primer marquès de Barberà, era el seu besnet. El camí del quatrecentista Francesc de Pinós al decimonònic arxiu de Barberà seria doncs el més natural». 
En resum, a més de la connexió vianista de Corella i Pinós, cal tenir present la relació de la família Alegre amb aquest entorn, i la relació de l'escriptor amb l'entorn de Joan II. Tot plegat apropa la voluntat literària d'Alegre a aquests ambients, tot i que per edat el nostre escriptor és encara un nen en època del príncep Carles, i desplega la seva ploma més tard, sota el regnat de Joan II. Ara bé, l'ambient de la cort del príncep podia molt possiblement haver marcat la seva formació literària, i influir en l'elecció de les traduccions i en l'estil de les seves obres sentimentals. Segurament la convulsió del conflicte civil degué reordenar aquests ambients, com mostren els canvis de bàndol de Francesc de Pinós o Pere Torroella. En els deu anys que dura el conflicte (I462-I472), després de la mort del príncep, la cort degué experimentar una dispersió. Alegre, que, com hem dit, es forma influït per aquest ambient, en vèncer Joan II i canviar la situació a la ciutat de Barcelona, podria haver volgut postular-se com un hereu primerenc d'aquell ambient a ulls del monarca, cosa que permetria explicar la dedicatòria del Sermó de amor a Joan II. Així, la continuïtat d'Alegre pot donarse per l'herència que recull de la cort del príncep en la seva etapa formativa i que desenvoluparà literàriament després del conflicte, quan se situa la major part de la seva producció, en una successió que trobem també en Pere Torroella.

¿És possible que Dela Mirambella, el mestre de la cort del príncep de Viana que educà Alegre, o bé Pere Torroella, amb qui Alegre es relaciona i que és membre de les corts del príncep i de Joan II, així com guia d'autors, haguessen empès el nostre autor a iniciar les Transformacions? Alegre escriu les Transformacions a l'època que hom situa la mort de Pinós. Potser va voler seguir i completar conscientment aquells «alguns libres» que diu que tenia la versió de Pinós?

Que sigui possible entreveure un ancestre comú entre Corella i Alegre resulta, naturalment, molt interessant, perquè això ressitua la feina traductora d'Alegre a les Transformacions i perfila una nova relació literària entre ells, d'aquesta manera deutora d'una tradició cortesana de Les metamorfosis influent en la seva prosa d'art i el seu món sentimental. En definitiva, l'ancestre es presentaria com un vincle nuclear d'aquesta tradició, especialment entre les obres mitològiques de la segona meitat del segle XV en el context de la literatura de cort, cosa que situa les Transformacions d'Alegre com un intent extemporani de recuperació d'aquesta tradició, i els elements ovidians d'Alegre, Corella o Martorell com una manifestació literària que podríem adscriure a aquesta tradició de Les metamorfosis sobre la qual avui hi ha tantes ombres.

No cal, en definitiva, dubtar de la influència de Corella en Alegre, atesa la consagració de Corella a la segona meitat del segle XV i les relacions entre la Tragédia de Caldesa i la Faula; però una altra cosa és atribuir als passatges comuns Corella-Alegre, d'entrada, a una dependència exclusiva de l’obra del valencià; com a mínim, de l'estadi de redacció que avui en preservem. La traducció del poeta romà, i el comentari a partir de Boccaccio, permetien a Alegre conèixer els mites clàssics en profunditat, i posicionar-se amb una certa auctoritas en relació a la seva interpretació al-legòrica; a més, hi ha el buit de tots els episodis de Les metamorfosis no traduïts per Pinós, que Alegre pot completar. Al cap i a la fi, si la formació del nostre escriptor l'apropa a l'ambient de la cort del príncep de Viana, i alguna de les seves obres a la de Joan II d'Aragó, percebem una successió cortesana que no resulta estranya al període, perquè també la notem en Pere Torroella o mossèn Avinyó. 